Check for updates

Cite this: RSC Adv., 2017, 7, 30770

Received 13th April 2017

Accepted 7th June 2017

DOI: $10.1039 / c 7 r a 04214 k$

rsc.li/rsc-advances

\section{Poly(arylene ether sulfone) bearing multiple benzyl-type quaternary ammonium pendants: preparation, stability and conductivity}

\author{
Qian Shi, ${ }^{\text {a }}$ Pei Chen, ${ }^{a}$ Jinfang Zhou, ${ }^{a}$ Qiang Weng, ${ }^{a}$ Xueliang Zhang, ${ }^{a}$ \\ Xinbing Chen (D)*a and Zhongwei $\mathrm{An}^{\mathrm{ab}}$
}

\begin{abstract}
A new difluoro aromatic ketone monomer, (2,6-difluorophenyl)[3,5-bis[(3,5-dimethylphenyl)methyl] phenyl]methanone, is developed to prepare a series of poly(arylene ether sulfone)s (PAES) bearing two pendant 3,5-dimethylphenyl groups via polycondensation reaction. The desired side-chain type PAESs containing multiple benzyl quaternary ammonium groups (QPAES(x/y)) are obtained by the corresponding bromomethylation and subsequent quaternization. Their properties, such as hydroxide conductivity, dimensional change, water uptake and alkaline stability, are investigated. Side-chain type membranes QPAES(x/y) with ion exchange capacities (IECS) of 0.96-1.22 mequiv. $\mathrm{g}^{-1}$ display anisotropic membrane swelling and hydroxide conductivity of $39.9-49.8 \mathrm{~ms} \mathrm{~cm}^{-1}$ at $80{ }^{\circ} \mathrm{C}$. The greater length and dense distribution of the benzyl-type quaternary ammonium pendants are probably responsible for the good hydroxide conductivity and alkaline stability. Meanwhile, the corresponding crosslinked membrane (CQPAES(1/4)) shows higher conductivity, lower membrane swelling, better oxidative stability and higher chemical stability in hot alkali solution $\left(80^{\circ} \mathrm{C}\right)$ than the uncrosslinked one with a comparable IEC value.
\end{abstract}

\section{Introduction}

As an efficient energy conversion technology, fuel cells have attracted great interest for stationary and mobile applications because of their high power density and low pollution levels. ${ }^{1,2}$ Anion exchange membrane (AEM) fuel cells (AEMFCs) are attracting growing attention over proton exchange membrane (PEM) fuel cells (PEMFCs), because they exhibit fast oxygen reduction kinetics and allow nonprecious metals as catalysts. ${ }^{3-5}$ The AEM plays a key role in an AEMFC, such as conducting hydroxide ions from cathode to anode, as well as preventing fuel crossover between anode and cathode. To be suitable for AEMFC applications, AEMs should meet some fundamental requirements such as high hydroxide conductivity, low swelling degree, and high alkaline stability, ${ }^{6-8}$ therefore a number of polymers bearing anion groups (quaternary ammonium, ${ }^{9-13}$ imidazolium, ${ }^{14-16}$ guanidinium, ${ }^{17}$ and phosphonium groups ${ }^{18,19}$ ) have been developed to act as AEMs, where the as-utilized polymers include poly(styrene), ${ }^{20,21}$ poly(arylene ether), ${ }^{22-26}$ poly (phenylene), ${ }^{27,28}$ poly(phenylene oxide). ${ }^{29,30}$ Among these AEMs, quaternized poly(styrene) based AEMs are commercially available. Recently, McKeown, Guiver and Xu et al. reported that

${ }^{a}$ Key Laboratory of Applied Surface and Colloid Chemistry (MOE), Shaanxi Key Laboratory for Advanced Energy Devices, Shaanxi Engineering Laboratory for Advanced Energy Technology, School of Materials Science and Engineering, Shaanxi Normal University, Xi'an 710119, PR China. E-mail: chenxinbing@snnu.edu.cn

${ }^{b} X i{ }^{\prime} a n$ Modern Chemistry Research Institute, Xi'an 710065, PR China microporous polymers based AEMs containing the V-shape rigid Tröger's base unit exhibited the high hydroxide conductivity up to $164.4 \mathrm{mS} \mathrm{cm}^{-1}\left(80{ }^{\circ} \mathrm{C}\right)$ with a relatively low ion exchange capacity (IEC) of 0.82 mequiv. $\mathrm{g}^{-1} \cdot{ }^{31}$ However, most of the developed AEMs need to solve the challenges such as low ionic conductivity, and/or low chemical stability of the cationic group and polymer matrix.

It is known that hydroxide ion mobility is primarily slower than protons in polymer electrolyte membrane, so increasing the ionic concentration (or IEC) of AEM is a general strategy to improve ionic conductivity. ${ }^{32}$ Nevertheless, a large IEC will obviously increases water uptake and swelling of the membrane, especially at elevated temperature, which brings negative effect on the mechanical property and durability of AEM. Zhang et al. reported that a high conductivity $(39 \mathrm{mS}$ $\left.\mathrm{cm}^{-1}\right)$ at $60{ }^{\circ} \mathrm{C}$ could be achieved for imidazolium functionalized poly(arylene ether sulfone)s (PAES), but its swelling ratio reached to $150 \%$ at $60{ }^{\circ} \mathrm{C}^{33}$ Employing side-chain type or block copolymer ionomer as AEM is another approach to achieve high hydroxide conductivity. Li et al. synthesized side-chain type PAES copolymers, whose properties were much better than those of main-chain type ones. For example, PAES-Q-90 with IEC of 1.68 mequiv. $\mathrm{g}^{-1}$ exhibited a high hydroxide conductivity of $93 \mathrm{mS} \mathrm{cm}^{-1}$ at $80^{\circ} \mathrm{C}$ and a high long-term stability in hot alkali solution, due to the side-chain induced microphase separation. $^{34}$ Some approaches are exploited to introduce anion groups on to the polymer side-chain, ${ }^{16,20}$ however, few side- 
chain type monomers are developed to build copolymers bearing pendant anion groups..$^{35,36}$

Recently, we prepared PAES-based AEMs containing pendant benzyl-type quaternary ammonium hydroxide groups, they displayed high long-term stability in hot alkali solution and reasonably high hydroxide conductivity. Their properties were improved via phenolate-based branched/crosslinking structure in membrane. ${ }^{36}$ To further investigate the effects of side-chain type monomer on the property of the resulting PAES-based AEMs, a new reactive difluoro aromatic ketone monomer bearing two pendent 3,5-dimethylphenyl groups, (2,6difluorophenyl)[3,5-bis[(3,5-dimethylphenyl)methyl $]$ phenyl] methanone (DFBDM), was prepared via a three-step reaction. DFBDM-based PAESs containing multiple benzyl quaternary ammonium pendant groups (QPAES $(x / y)$ ) were obtained by polycondensation, followed by reactions of bromomethylation and subsequent quaternization. Their properties, such as hydroxide conductivity, dimensional change, water uptake, methanol permeability, oxidative and alkaline stability, were investigated and compared with those of the corresponding DFBDM-based crosslinked membrane.

\section{Experimental section}

\subsection{Materials}

3,5-Dimethylphenylboronic acid was acquired from Beijing Zhongsheng Huateng Technology Co. Ltd. 2,6-Difluorobenzonitrile and 4,4'-difluorodiphenyl sulfone (DFDPS) were obtained from Zhejiang Shouerfu Chemical Co. Ltd. 4,4'Biphenol and 2,4,6-tris(dimethylaminomethyl)phenol (TAP) were purchased from Aladdin Reagent. 1-Bromo-3,5dimethylbenzene was acquired from Shanghai Darui Finechemical Co. Ltd. Other organic solvents and chemical reagents were purchased from Sinopharm Chemical Reagent. Prior to use, 4,4'-biphenol (BP) was sublimated, while dimethyl sulfoxide (DMSO) was dehydrated with 4 Å molecular sieve.

\subsection{Synthesis of monomer}

2.2.1. Synthesis of 5-(2,6-difluorobenzyl)-1,3-dimethylbenzene (DFDB). The Grignard reagent, 3,5-dimethylphenyl magnesium bromide, was prepared by refluxing $3.36 \mathrm{~g}$ ( 0.14 mol) of magnesium in $100 \mathrm{~mL}$ of absolute diethyl ether and $25.91 \mathrm{~g}(0.14 \mathrm{~mol})$ of 1-bromo-3,5-dimethylbenzene under $\mathrm{N}_{2}$ protection. To the solution of 3,5-dimethylphenyl magnesium bromide in absolute diethyl ether, $19.47 \mathrm{~g}$ (0.14 mol) of 2,6difluorobenzonitrile in $100 \mathrm{~mL}$ of absolute diethyl ether was added slowly with stirring and refluxing under $\mathrm{N}_{2}$ atmosphere. The reaction mixture was stirred under reflux for $6 \mathrm{~h}$, and the reaction progress was monitored by thin layer chromatography (TLC). Then the reaction was quenched with $80 \mathrm{~mL}$ of $0.1 \mathrm{M}$ hydrochloric acid, keeping the temperature below $25{ }^{\circ} \mathrm{C}$. The ether layer was separated, and hydrolyzed in $200 \mathrm{~mL}$ of $1 \mathrm{M}$ hydrochloric acid under reflux for $6 \mathrm{~h}$. After hydrolysis, the ether layer was separated, washed with water to neutral, dried over anhydrous magnesium sulfate, and then concentrated under reduced pressure to yield crude product. The crude product was distilled under reduced pressure to give DFDB with yield of $71 \%$. Pale yellow crystal with $\mathrm{mp} 85.6-86.3{ }^{\circ} \mathrm{C}$ was obtained finally.

Characterization data of DFDB: ${ }^{1} \mathrm{H}-\mathrm{NMR}$ (300 MHz, DMSO$d_{6}$, TMS): $\delta(\mathrm{ppm}): 7.70(\mathrm{~s}, 1 \mathrm{H}), 7.45(\mathrm{~s}, 2 \mathrm{H}), 7.40(\mathrm{~s}, 1 \mathrm{H}), 7.30(\mathrm{~m}$, 2H), 2.34 (s, 6H). IR (KBr, pellet, $\left.\mathrm{cm}^{-1}\right): 3066,3032,2918,1668$, 1514, 1460, 1228. MS (m/z (rel. int\%)): 246.17 (65) $\left[\mathrm{M}^{+}\right], 141.04$ (34) $\left[\mathrm{C}_{7} \mathrm{H}_{3} \mathrm{OF}_{2}^{+}\right], 133.10$ (100) $\left[\mathrm{C}_{9} \mathrm{H}_{9} \mathrm{O}^{+}\right], 105.09(24)\left[\mathrm{C}_{8} \mathrm{H}_{9}{ }^{+}\right]$.

2.2.2. Synthesis of 5-(2,6-difluorobenzyl)-1,3-dibromomethylbenzene (DFDBB). To a $100 \mathrm{~mL}$ single-neck flask were added $1.22 \mathrm{~g}$ of $N$-bromosuccinimide (NBS, $6.85 \mathrm{mmol}$ ), $1.00 \mathrm{~g}$ of DFDB (2.03 mmol), $0.06 \mathrm{~g}$ of 2,2-azobisisobutyronitrile (AIBN, $0.37 \mathrm{mmol}$ ) and $50 \mathrm{~mL}$ of chloroform. The reaction mixture was stirred under reflux for $4.5 \mathrm{~h}$. After removal of the solvent in vacuo, the residue was purified via column chromatography on silica gel using petroleum ether/ethyl acetate (PE/EA, 100/1) as eluent to give purity above $86 \%$ for gas chromatography (GC) measurement. White crystals were obtained with yield of $61.2 \%$ and mp 106.3-109.1 ${ }^{\circ} \mathrm{C}$.

Characterization data of DFDBB: ${ }^{1} \mathrm{H}-\mathrm{NMR}\left(300 \mathrm{MHz}, \mathrm{CDCl}_{3}\right.$, TMS): $\delta(\mathrm{ppm}): 7.79(\mathrm{~s}, 2 \mathrm{H}), 7.70(\mathrm{~s}, 1 \mathrm{H}), 7.47(\mathrm{~m}, 1 \mathrm{H}) 7.04(\mathrm{t}, J=$ $7.5 \mathrm{~Hz}, 2 \mathrm{H}), 4.42(\mathrm{~s}, 4 \mathrm{H}) .{ }^{13} \mathrm{C} \mathrm{NMR}\left(100 \mathrm{MHz}, \mathrm{CDCl}_{3}\right), \delta(\mathrm{ppm})$ $187.66(\mathrm{~s}), 159.91\left(\mathrm{dd},{ }^{1} J_{\mathrm{FC}}=251 \mathrm{~Hz},{ }^{3} J_{\mathrm{FC}}=7 \mathrm{~Hz}\right), 139.50(\mathrm{~s})$, $137.93(\mathrm{~s}), 135.21(\mathrm{~s}), 132.60\left(\mathrm{t},{ }^{3} J_{\mathrm{FC}}=10 \mathrm{~Hz}\right), 116.43\left(\mathrm{t},{ }^{2} J_{\mathrm{FC}}=21\right.$ $\mathrm{Hz}), 112.22\left(\mathrm{dt},{ }^{2} J_{\mathrm{FC}}=20 \mathrm{~Hz},{ }^{4} J_{\mathrm{FC}}=6 \mathrm{~Hz},{ }^{4} J_{\mathrm{FC}}=3 \mathrm{~Hz}\right), 31.74(\mathrm{~s})$. IR (KBr, pellet, $\mathrm{cm}^{-1}$ ): 2979, 2977, 1670, 1598, 1463, 1454, 1228, 698, 597. MS ( $\mathrm{m} / \mathrm{z}$ (rel. int\%)): 402.98 (51) $\left[\mathrm{M}^{+}\right], 322.14$ (19) $\left[\mathrm{C}_{15} \mathrm{H}_{10} \mathrm{BrF}_{2} \mathrm{O}^{+}\right], 141.07$ (56) $\left[\mathrm{C}_{7} \mathrm{H}_{3} \mathrm{~F}_{2} \mathrm{O}^{+}\right]$.

2.2.3. Synthesis of (2,6-difluorophenyl) $[3,5$-bis $[(3,5-$ dimethylphenyl)methyl]phenyl]methanone (DFBDM). To a 250 $\mathrm{mL}$ round-bottom flask equipped with a condenser, $1.00 \mathrm{~g}$ of DFDBB (2.47 mmol), $1.22 \mathrm{~g}$ of 3,5-dimethylphenylboronic acid ( $8.13 \mathrm{mmol}), 1.06 \mathrm{~g}$ of sodium carbonate $(9.92 \mathrm{mmol}), 0.14 \mathrm{~g}$ of tetrakis(triphenylphosphine)palladium $(0.12 \mathrm{mmol}), 0.04 \mathrm{~g}$ of tetrabutyl ammonium bromide $(0.12 \mathrm{mmol}), 72 \mathrm{~mL}$ of tetrahydrofuran and $24 \mathrm{~mL}$ of distilled water were added. The reaction system was stirred at reflux for $12 \mathrm{~h}$ under $\mathrm{N}_{2}$ protection. After completion of the reaction, the mixture was diluted with water and extracted with methylene chloride for three times. The combined organic phase was dried over anhydrous magnesium sulfate. After removal of the solvent in vacuo, the residue was purified via column chromatography on silica gel using PE/EA $(100 / 1)$ as eluent to give purity above $99 \%$ for GC measurement. White crystals were obtained with yield of $64.7 \%$ and $\mathrm{mp}$ 92.8-94.6 ${ }^{\circ} \mathrm{C}$.

Characterization data of DFBDM: ${ }^{1} \mathrm{H}-\mathrm{NMR}(300 \mathrm{MHz}, \mathrm{DMSO}-$ $d_{6}$, TMS): $\delta(\mathrm{ppm}): 7.67(\mathrm{~m}, 1 \mathrm{H}), 7.48(\mathrm{~s}, 3 \mathrm{H}), 7.26(\mathrm{t}, J=8.0 \mathrm{~Hz}$, $2 \mathrm{H}), 6.78(\mathrm{~d}, J=6.6 \mathrm{~Hz}, 2 \mathrm{H}), 3.89(\mathrm{~s}, 4 \mathrm{H}), 2.19$ (s, 12H). ${ }^{13} \mathrm{C} \mathrm{NMR}$ $\left(100 \mathrm{MHz}, \mathrm{CDCl}_{3}\right), \delta(\mathrm{ppm}) 189.20(\mathrm{~s}), 159.90\left(\mathrm{dd},{ }^{1} J_{\mathrm{FC}}=250 \mathrm{~Hz}\right.$, ${ }^{3} J_{\mathrm{FC}}=8 \mathrm{~Hz}$ ), $142.27(\mathrm{~s}), 140.18(\mathrm{~s}), 138.17(\mathrm{~s}), 137.17$ (s), 135.82 (s), $131.91\left(\mathrm{t},{ }^{3} J_{\mathrm{FC}}=10 \mathrm{~Hz}\right), 128.23(\mathrm{~s}), 128.05(\mathrm{~s}), 126.78(\mathrm{~s})$, $117.32\left(\mathrm{t},{ }^{2} J_{\mathrm{FC}}=22 \mathrm{~Hz}\right), 111.95\left(\mathrm{dt},{ }^{2} J_{\mathrm{FC}}=19 \mathrm{~Hz},{ }^{4} J_{\mathrm{FC}}=5 \mathrm{~Hz},{ }^{4^{\prime}} J_{\mathrm{FC}}\right.$ $=2 \mathrm{~Hz}$ ), 41.50 (s), 21.38 (s). IR (KBr, pellet, $\mathrm{cm}^{-1}$ ): 3012, 2923, 2862, 1670, 1606, 1598, 1458, 1382, 1301, 1228, 1222, 1122, 1006, 725. MS ( $\mathrm{m} / \mathrm{z}$ (rel. int\%)): 454.36 (51) $\left[\mathrm{M}^{+}\right], 335.26$ (35) $\left[\mathrm{C}_{22} \mathrm{H}_{17} \mathrm{~F}_{2} \mathrm{O}^{+}\right], 141.07$ (100) $\left[\mathrm{C}_{7} \mathrm{H}_{3} \mathrm{~F}_{2} \mathrm{O}^{+}\right], 119.11(42)\left[\mathrm{C}_{9} \mathrm{H}_{11}{ }^{+}\right]$. 


\subsection{Preparation of PAES copolymer}

2.3.1. Preparation of PAES copolymer bearing pendent multiple methyl groups (PAES $(\boldsymbol{x} / \boldsymbol{y})-\mathbf{M e})$. As an example, the synthetic process of PAES(1/4)-Me is described here. $0.512 \mathrm{~g}$ $(2.75 \mathrm{mmol})$ of BP, $0.140 \mathrm{~g}(0.55 \mathrm{mmol})$ of DFDPS, $0.456 \mathrm{~g}$ (3.30 $\mathrm{mmol})$ of anhydrous potassium carbonate, $1.000 \mathrm{~g}(2.20 \mathrm{mmol})$ of DFBDM, $9 \mathrm{~mL}$ of DMSO and $9 \mathrm{~mL}$ of toluene were added to a dry three-neck flask under nitrogen flow with stirring. The reaction mixture was stirred at $140{ }^{\circ} \mathrm{C}$ for $4 \mathrm{~h}$, and then slowly heated to $170{ }^{\circ} \mathrm{C}$ to remove water produced in reaction. The system was kept at $170^{\circ} \mathrm{C}$ for several hours when the viscosity of the solution was observed to increase dramatically. The resulting highly viscous solution was slowly poured into water, and the precipitate (PAES(1/4)-Me) was dried at $100{ }^{\circ} \mathrm{C}$ in vacuum for $24 \mathrm{~h}$ after thoroughly washing with water and methanol, respectively.

2.3.2. Bromomethylation of PAES copolymer (PAES $(x / y)$ Br). The brominated copolymer PAES(1/4)-Br is synthesized via bromomethylation of PAES(1/4)-Me according to following procedure. To a $100 \mathrm{~mL}$ three-neck flask equipped with a condenser and a nitrogen inlet, $0.50 \mathrm{~g}$ of PAES(1/4)-Me was dissolved in $50 \mathrm{~mL}$ of chloroform under nitrogen flow with stirring. Then $1.30 \mathrm{~g}$ of NBS $(7.30 \mathrm{mmol})$ and $0.07 \mathrm{~g}(0.43 \mathrm{mmol})$ of AIBN were added to the homogeneous solution, and the reaction mixture was heated to $60{ }^{\circ} \mathrm{C}$ and kept at this temperature for $24 \mathrm{~h}$ with stirring. After cooling to room temperature, the resulting solution was slowly poured into acetone. The obtained precipitate (PAES(1/4)-Br) was dried below $40{ }^{\circ} \mathrm{C}$ in vacuum for $24 \mathrm{~h}$ after thoroughly washing with acetone.

\subsection{Preparation of anion exchange membrane (QPAES $(x / y))$}

A typical procedure of casting method is adopted to prepare AEM as follows (QPAES(1/4) as example). $1.00 \mathrm{~g}$ of PAES(1/4)-Br was dissolved in $20 \mathrm{~mL}$ of chloroform under stirring to obtain $\operatorname{PAES}(x / y)$-Br copolymer solution with a concentration about $5 \%$ (weight/volume, w/v), the filtered solution was then cast onto a glass plate. After drying at room temperature for $24 \mathrm{~h}$, the ascast membrane was delicately peeled in the deionized water. The resulting membrane was then quaternary-aminated in trimethylamine aqueous solution $(33 \%)$ for $72 \mathrm{~h}$ at $30{ }^{\circ} \mathrm{C}$, followed by hydroxide exchange in $\mathrm{NaOH}$ aqueous solution (1 M) for 48 h. The QPAES(1/4) anion exchange membrane was finally obtained after washing with deionized water till the rinsed water becomes neutral. The prepared AEMs are strong in both dry and wet state with thickness of 30-50 $\mu \mathrm{m}$.

\subsection{Preparation of crosslinked/branched anion exchange membrane (CQPAES $(x / y))$}

The fabrication of crosslinked/branched AEM CQPAES(1/4) is described here as an example. $0.5 \mathrm{~g}$ of PAES(1/4)-Br was dissolved in $N, N$-dimethylformamide (DMF) to prepare a $1 \mathrm{wt} \%$ $\operatorname{PAES}(x / y)$-Br solution. After filtering, a given amount of TAP solution in DMF was added dropwise into the system under stirring at room temperature for $30 \mathrm{~min}$. The mixture was then poured onto a glass plate and kept at $50{ }^{\circ} \mathrm{C}$ for $48 \mathrm{~h}$. The as-cast crosslinked/branched membrane was further dried in vacuum at $50{ }^{\circ} \mathrm{C}$ for $12 \mathrm{~h}$, and peeled off from the glass plate in deionized water. The subsequent quaternization and hydroxide exchange procedures were carried out using above method for $\operatorname{QPAES}(x / y)$.

\subsection{Characterization}

Spectral methods were employed to confirm the structures of monomer, intermediates and copolymers. Fourier transform infrared (FT-IR) spectra were recorded on a Bruker Equinox 55 spectrometer with absorption spectra from 4000 to $400 \mathrm{~cm}^{-1}$. Proton nuclear magnetic resonance $\left({ }^{1} \mathrm{H}-\mathrm{NMR}\right)$ spectra were performed on a Bruker AV 300 instrument with tetramethyl silane (TMS) as internal standard and $\mathrm{CDCl}_{3}$ or DMSO- $d_{6}$ as solvent. Mass spectra were obtained from GC/EI-MS Thermo DSQ II instrument with $\mathrm{m} / \mathrm{z}$ 50-650. X-ray photoelectron spectroscopy (XPS) spectra were recorded on a Kratos Axis Ultra DLD photoelectron spectrometer using non-monochromatized $\mathrm{Mg}$ $\mathrm{K} \alpha$ radiation $(1253.6 \mathrm{eV}$ ).

Molecular weight and molecular weight distribution of the copolymers were acquired from Waters-Breeze gel permeation chromatography (GPC) system. The mechanical property was obtained from an Instron 3342 universal testing machine with a stretching rate of $0.2 \mathrm{~cm} \mathrm{~min}^{-1}$ at room temperature. Thermal stability was recorded on thermogravimetric analysis using a TA $600 \mathrm{SDT}$ instrument with heating rate of $10{ }^{\circ} \mathrm{C} \mathrm{min}{ }^{-1}$ in helium.

\subsection{Measurements}

IEC was determined by a back titration method, where a membrane sample in quaternary ammonium hydroxide form was soaked in $50 \mathrm{~mL}$ of $\mathrm{HCl}$ solution $(0.01 \mathrm{M})$ at $45^{\circ} \mathrm{C}$ for $72 \mathrm{~h}$ to consume $\mathrm{OH}^{-}$ion with $\mathrm{H}^{+}$ion, and the system was sealed. Then the remaining $\mathrm{H}^{+}$ion in solution was titrated with a $0.05 \mathrm{M}$ $\mathrm{NaOH}$ solution using phenolphthalein as the indicator. The IEC value can be obtained via dividing the mole difference between $\mathrm{HCl}$ and $\mathrm{NaOH}$ by sample quantities (in grams).

Water uptake (WU) and dimensional change (through-plane $\left(\Delta t_{\mathrm{c}}\right)$ and in-plane $\left.\left(\Delta l_{\mathrm{c}}\right)\right)$ were determined by weight difference and dimensional (thickness, length) difference between the dry and wet circular membranes, respectively, where membrane swelling ratio $\left(\Delta_{t / l}\right)$ was calculated via dividing $\Delta t_{\mathrm{c}}$ by $\Delta l_{\mathrm{c}}$. The dry weight $\left(W_{\mathrm{d}}\right)$ and dimensional $\left(t_{\mathrm{d}}, l_{\mathrm{d}}\right)$ data of the membrane were obtained after drying in vacuum at $60{ }^{\circ} \mathrm{C}$ for $24 \mathrm{~h}$, whereas the wet weight $(W)$ and dimensional $(t, l)$ data were acquired after quickly wiping off the water from the surface of the membrane which was immersed into deionized water at a given temperature. Accordingly, $\mathrm{WU}, \Delta t_{\mathrm{c}}$ and $\Delta l_{\mathrm{c}}$ were calculated via the following equations,

$$
\begin{gathered}
\mathrm{WU}=\left[\left(W-W_{\mathrm{d}}\right) / W_{\mathrm{d}}\right] \times 100 \% \\
\Delta t_{\mathrm{c}}=\left[\left(t-t_{\mathrm{d}}\right) / t_{\mathrm{d}}\right] \times 100 \% \\
\Delta l_{\mathrm{c}}=\left[\left(l-l_{\mathrm{d}}\right) / l_{\mathrm{d}}\right] \times 100 \%
\end{gathered}
$$


Hydroxide conductivity $(\sigma)$ was recorded on an electrochemical impedance spectroscopy instrument (Hioki 3532-80) over the frequency range from $100 \mathrm{~Hz}$ to $100 \mathrm{kHz}$. As reported in literature, ${ }^{36,37}$ a membrane sample was set in the cell with two pairs of platinum plate electrodes to form a sandwich structure, and then the measurement was performed in deionized water at different temperatures. The conductivity was obtained according to the following equation,

$$
\sigma=d /\left(t_{\mathrm{s}} w_{\mathrm{s}} R\right)
$$

where $d, t_{\mathrm{s}}$ and $w_{\mathrm{s}}$ represent membrane length between the two electrodes, the swollen membrane thickness and width at a given temperature, respectively. To avoid the influence of carbon dioxide, the prepared AEMs were kept and sealed in boiled deionized water, meanwhile, the deionized water for $\sigma$ measurement was boiled for several minutes before test.

Methanol permeability $\left(P_{\mathrm{M}}\right)$ was measured via a liquid permeation cell including two compartments, ${ }^{36,37}$ which was composed of feed part, permeate part and water-swollen membrane sample. A given amount of methanol feed solution (32 wt\%) and deionized water were added into the two compartments separated by the membrane sample, respectively. The permeability measurement was carried out at $25{ }^{\circ} \mathrm{C}$ with stirring in the feed and permeate parts. The change of the methanol concentration in feed and permeate was monitored via Shimadzu GC2014C gas chromatography apparatus. The $P_{\mathrm{M}}$ data was calculated from the following equation,

$$
P_{\mathrm{M}}=C_{\mathrm{p}} V_{\mathrm{p}} L /\left(A C_{\mathrm{f}} t\right)
$$

where $C_{\mathrm{f}}$ and $C_{\mathrm{p}}$ refer to the methanol concentration in feed and permeate at time $t$, while $L, A$ and $V_{\mathrm{p}}$ represent the effective membrane thickness, membrane area and the permeate volume, respectively.

\section{Results and discussion}

\subsection{Synthesis and characterization of monomer}

As shown in Fig. 1, DFBDM is prepared via a three-step synthetic methodology composed of nucleophilic addition,

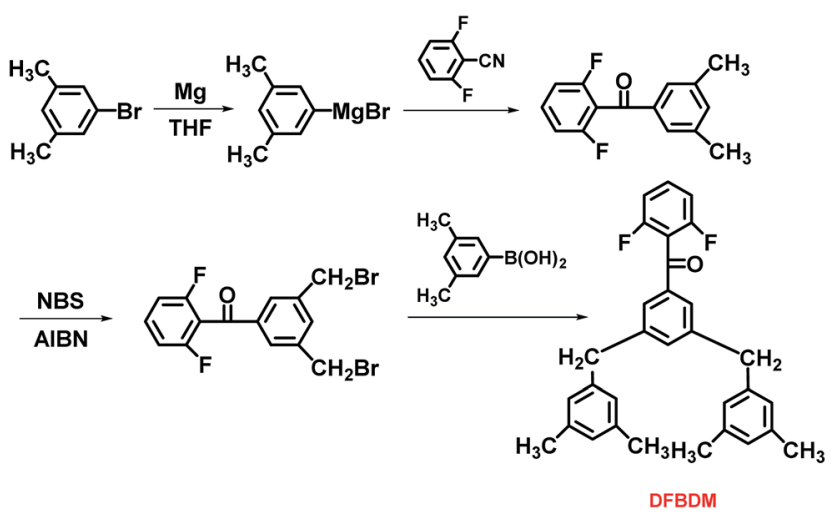

Fig. 1 Synthetic route of difluoro monomer DFBDM. bromomethylation, and Suzuki coupling reactions, where the intermediate 5-(2,6-difluorobenzyl)-1,3-dimethylbenzene is obtained through the nucleophilic addition of 3,5-dimethylphenyl magnesium bromide to 2,6-difluorobenzonitrile, followed by the bromomethylation with NBS as bromination reagent and AIBN as initiator, and finally reacted with 3,5-dimethylphenylboronic acid using tetrakis(triphenylphosphine)palladium as catalyst to achieve the reactive difluoro aromatic ketone monomer bearing two pendent 3,5-dimethylphenyl groups. It is noted that two brominated intermediates can be produced during bromomethylation reaction, including dibrominated intermediate DFDBB and monobrominated intermediate compound. Both of them can be utilized to prepare new difluoro aromatic ketone monomers via subsequent Suzuki coupling reaction, whereas the main attention is focused on DFBDM derived from dibrominated monomer DFDBB in this manuscript.

The structures of the monomer DFBDM and the corresponding intermediates were confirmed via FT-IR, ${ }^{1} \mathrm{H}-\mathrm{NMR}$, and GC/EI-MS, respectively, as shown in the Experimental section. For IR data of DFBDM, the peaks at 1606 and $1598 \mathrm{~cm}^{-1}$ are attributed to vibration of the phenyl ring, while the peaks at 1670 and $1006 \mathrm{~cm}^{-1}$ are assigned as vibrations of $\mathrm{C}=\mathrm{O}$ bond and $\mathrm{C}-\mathrm{F}$ bond, respectively. The absorption bands at 1458 and $1382 \mathrm{~cm}^{-1}$ are ascribed to vibration of $\mathrm{C}-\mathrm{H}$ bond in methyl and methylene groups. The peak of the molecular ion appears at $\mathrm{m} / \mathrm{z}$ 454.36 in GC/EI-MS spectrum, which is consistent with the theoretical molecular weight of 454.56 for DFBDM. In ${ }^{1} \mathrm{H}-\mathrm{NMR}$ spectra (Fig. 2), the type and quantity of the protons are in accordance with DFBDM and the intermediate molecules, where the methyl and methylene protons appear at 2.19 and 3.89 ppm, respectively. From ${ }^{13} \mathrm{C}-\mathrm{NMR}$ spectrum, the signals at $159.90,131.91,117.32$, and 111.95 ppm are assigned to carbons in difluorophenyl unit, and the peaks at 189.20, 41.55, and $21.38 \mathrm{ppm}$ are ascribed to carbons in carbonyl, methylene, and methyl groups, respectively. These results prove that the prepared monomer has the proposed structure for DFBDM.

\subsection{Synthesis and characterization of copolymer}

DFBDM-based PAES copolymer BP-DFDPS/DFBDM $(x / y)$-Me (coded as $\operatorname{PAES}(x / y)$-Me), where $x / y$ represents the mole feed ratio of DFDPS to DFBDM, is prepared by a one-pot high temperature polycondensation reaction (Fig. 3) with yield higher than $95 \%$. The feed ratio $(x / y)$ is set in the range from $1 / 3$ to $1 / 4$ to ensure the proper IEC value, as shown in Table 1 . The prepared copolymers $\operatorname{PAES}(x / y)$-Me have reduced viscosity of 0.46-0.62 $\mathrm{dL} \mathrm{g}^{-1}$ with number-average molecular weight of 40 500-65 400 and polydispersity index of $1.42-1.67$ by GPC (Table 2), indicating an acceptable high molecular weight that is enough for casting a tough membrane. The corresponding brominated PAES copolymer (coded as $\operatorname{PAES}(x / y)$-Br) is obtained by bromomethylation of $\operatorname{PAES}(x / y)$-Me with yield about $95 \%$.

The structures of the copolymers were identified by FT-IR and ${ }^{1} \mathrm{H}$-NMR spectra. Fig. 4 shows the protons of PAES(1/4)Me and PAES(1/4)-Br. For PAES(1/4)-Me in Fig. 4(a), the protons of methyl and methylene groups $\left(\mathrm{H}_{1}, \mathrm{H}_{\mathrm{k}}\right)$ appear at 2.21 and $3.87 \mathrm{ppm}$, respectively, while two kinds of phenyl protons in 


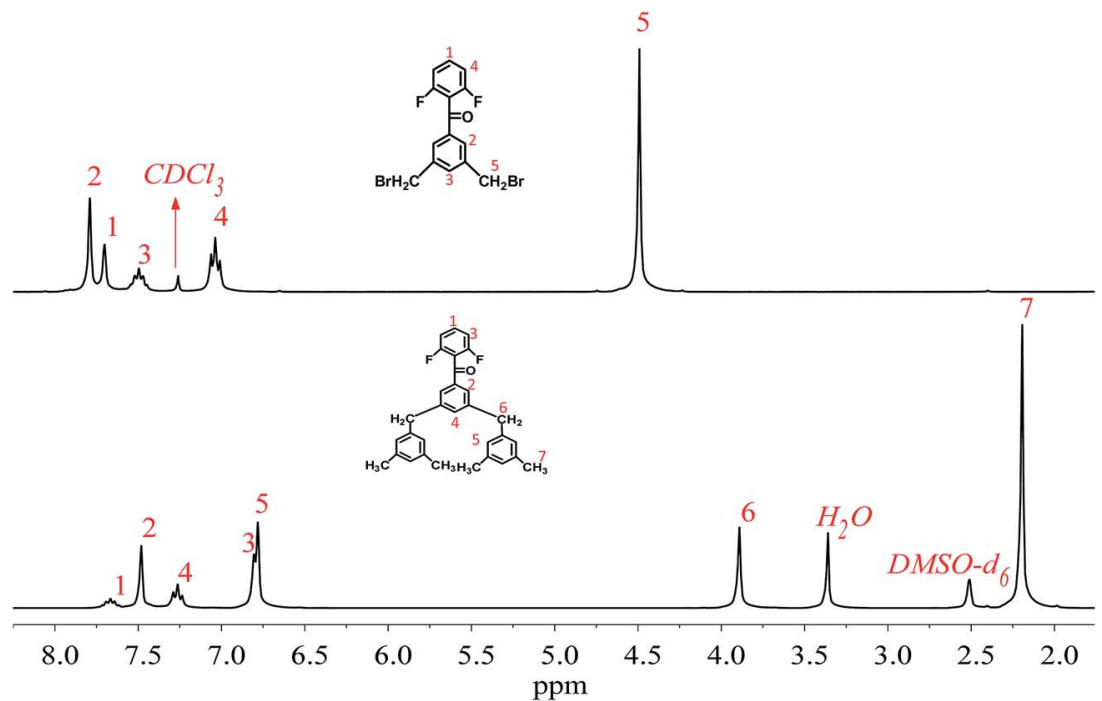

Fig. $2{ }^{1} \mathrm{H}$-NMR spectra of DFBDM and brominated intermediate.

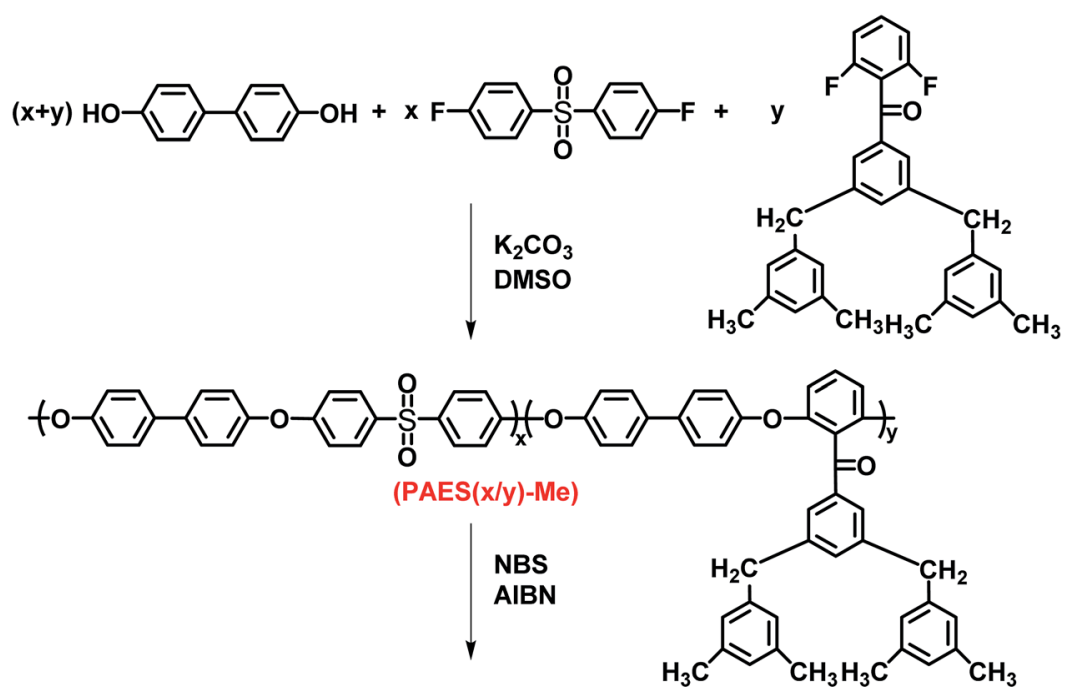<smiles>COc1ccc(-c2ccc(Oc3ccc(S(=O)(=O)c4ccc(Oc5ccc(-c6ccc(Oc7ccccc7)cc6)cc5)cc4)cc3)cc2)cc1</smiles>

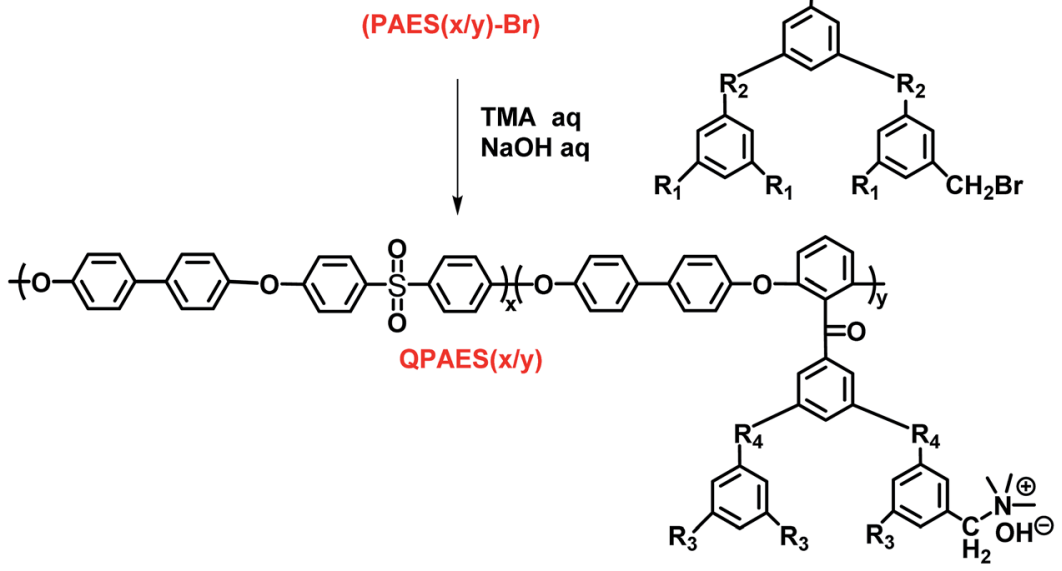

$\mathrm{x}: \mathrm{y}=1 / 3,1 / 4 ; \mathrm{R}_{1}=\mathrm{CH}_{3}, \mathrm{CH}_{2} \mathrm{Br}, \mathrm{CHBr}_{2} ; \mathrm{R}_{2}=\mathrm{CHBr}, \mathrm{CBr}_{2}$;

$\mathrm{R}_{3}=\mathrm{CH}_{3}, \mathrm{CH}_{2} \mathrm{~N}^{\oplus}\left(\mathrm{CH}_{3}\right)_{3} \mathrm{OH}, \mathrm{CHBr}_{2} ; \mathbf{R}_{4}=\mathrm{CHN}^{\oplus}\left(\mathrm{CH}_{3}\right)_{3} \mathrm{OH}^{\ominus} \mathrm{CBr}_{2}$;

Fig. 3 Synthetic route of side-chain type QPAES(x/y). 
Table 1 Basic properties of side-chain type quaternized PAES membranes ${ }^{a}$

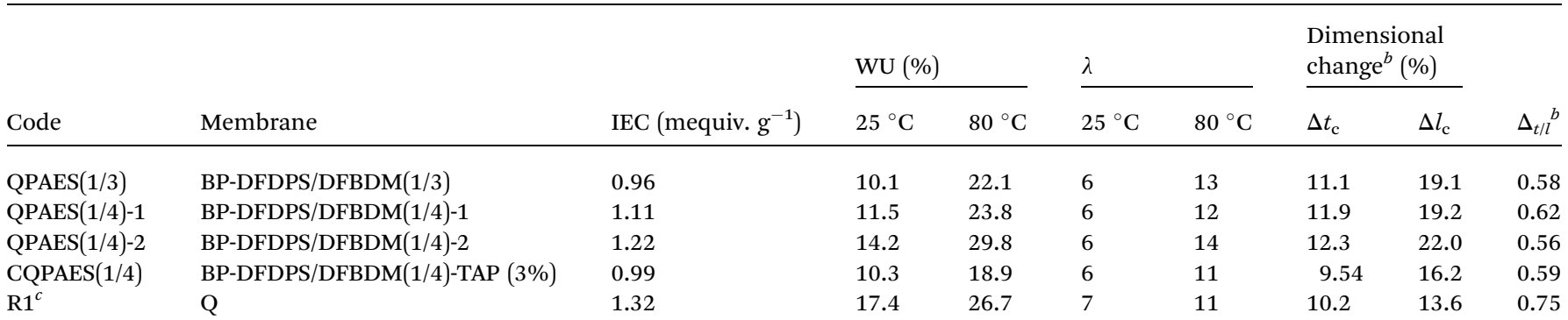

${ }^{a}$ The experimental errors for IEC, WU and size change are $\pm 1 \%, \pm 2 \%$ and $\pm 3 \%$, respectively. ${ }^{b}$ At $80{ }^{\circ} \mathrm{C} .{ }^{c}$ Ref. 36 .

Table 2 Viscosity and molecular weight of side-chain type PAES

\begin{tabular}{llll}
\hline Code & $\eta_{\mathrm{r}}{ }^{a}\left(\mathrm{dL} \mathrm{g}^{-1}\right)$ & $M_{\mathrm{n}} \times 10^{4}\left(\mathrm{~g} \mathrm{~mol}^{-1}\right)$ & $M_{\mathrm{w}} \times 10^{4}\left(\mathrm{~g} \mathrm{~mol}^{-1}\right)$ \\
\hline PAES(1/3)-Me & 0.46 & 4.05 & 5.74 \\
PAES(1/4)-Me & 0.62 & 6.54 & 10.9
\end{tabular}

${ }^{a}$ Concentration of $0.5 \mathrm{~g} \mathrm{dL}^{-1}$ in chloroform at $35^{\circ} \mathrm{C}$, the experimental error for $\eta_{\mathrm{r}}$ is $\pm 3 \%$.

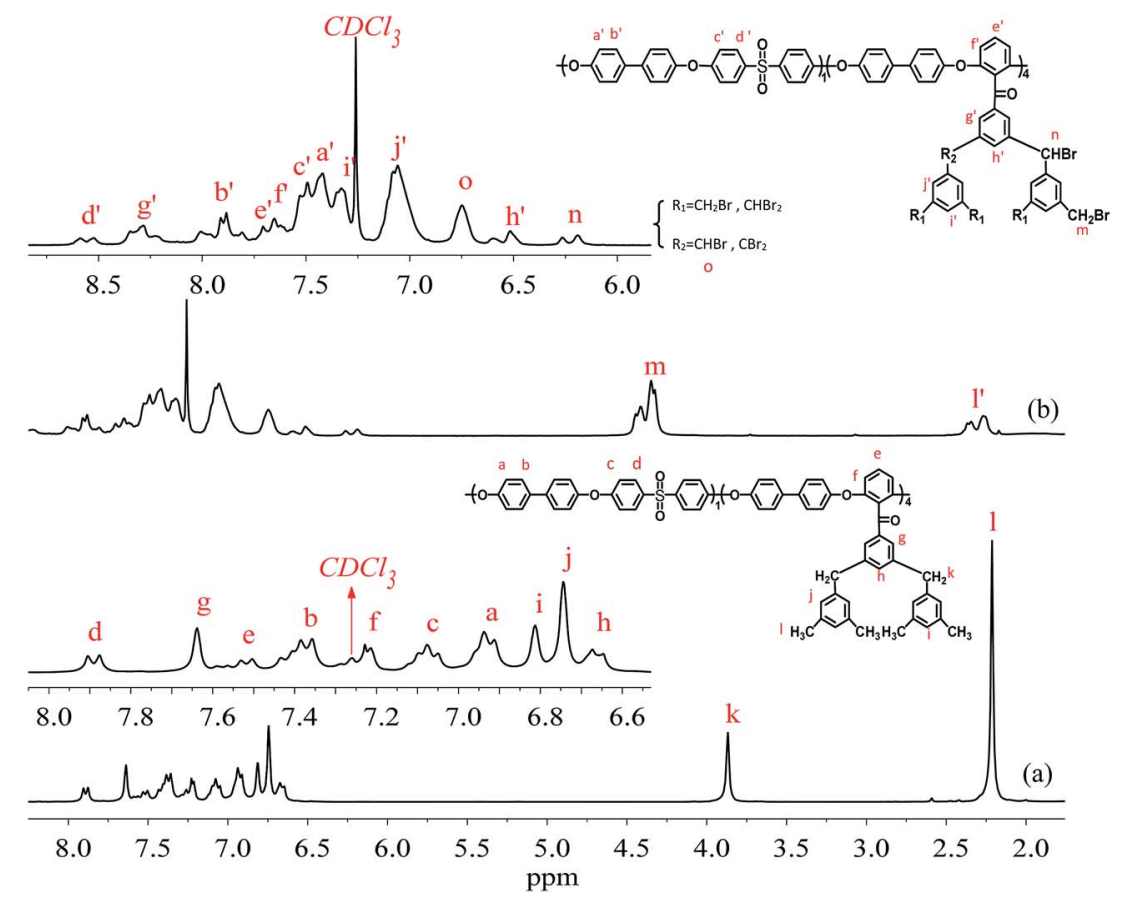

Fig. $4{ }^{1} \mathrm{H}$-NMR spectra of PAES(1/4)-Me (a) and PAES(1/4)-Br (b).

3,5-dimethylphenyl moiety $\left(\mathrm{H}_{\mathrm{j}}, \mathrm{H}_{\mathrm{i}}\right)$ appear at 6.74 and $6.81 \mathrm{ppm}$ due to the electron-donating effect of the linked methyl and methylene group, indicating the incorporation of DFBDM into copolymer. The peak at $7.89 \mathrm{ppm}$ is assigned to the aromatic proton at the ortho position to the electron-withdrawing sulfone linkage $\left(\mathrm{H}_{\mathrm{d}}\right)$, suggesting the incorporation of DFDPS into copolymer. The protons of $\operatorname{PAES}(1 / 4)-\mathrm{Br}$ copolymer are labelled in Fig. 4(b), where the characteristic peaks at 4.39, 6.23 and $6.75 \mathrm{ppm}$ are assigned to the protons of brominated methyl and methylene groups, $\mathrm{CH}_{2} \mathrm{Br}\left(\mathrm{H}_{\mathrm{m}}\right), \mathrm{CHBr}\left(\mathrm{H}_{\mathrm{n}}\right)$, and $\mathrm{CHBr}_{2}\left(\mathrm{H}_{\mathrm{o}}\right)$, respectively. The small peaks at 2.18-2.49 ppm belong to the protons of unreacted methyl group $\left(\mathrm{H}_{\mathrm{l}^{\prime}}\right)$. From Fig. 5, it is found that the IR spectra between PAES(1/4)-Br and PAES(1/4)-Me are roughly same, but the intensity of the characteristic peak of methyl group at $2918 \mathrm{~cm}^{-1}$ is reduced obviously, and the characteristic peak of $\mathrm{C}-\mathrm{Br}$ bond appear at 603 $\mathrm{cm}^{-1}$ for PAES(1/4)-Br, indicating the formation of brominated copolymers. 


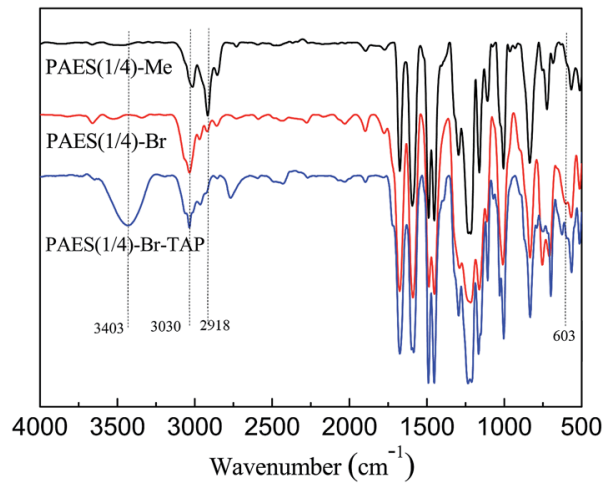

Fig. 5 IR spectra of PAES(1/4)-Me, PAES(1/4)- $\mathrm{Br}$ and PAES(1/4)- $\mathrm{Br}-$ TAP.

Crosslinked/branched copolymer is obtained via quaternization reaction between copolymer $\operatorname{PAES}(x / y)$ - $\mathrm{Br}$ and crosslinker TAP, as shown in Fig. 6, where the aromatic side-chain quaternary ammonium groups and phenolic moiety are introduced in the copolymer with crosslinked/branched structures at the same time. In our previous study, a high crosslinking degree can be achieved with the molar feed ratio of TAP/bromomethyl groups up to $15 \% .{ }^{36}$ However, the obvious gelation occurs in DMF solution when the feed ratio of TAP/bromomethyl exceeds $3 \%$ for the present DFBDM-based PAES $(x / y)$-Br copolymer. In the experiment, a TAP solution in DMF (3 wt $\%$ ) was adopted and added dropwise slowly into PAES $(x / y)$-Br copolymer solution in DMF (1 $\mathrm{wt} \%)$. It is noted that high concentration or quick addition of TAP solution will lead to appearance of gelation in reaction system.

\subsection{Preparation and characterization of crosslinked/ branched copolymer}

Compared with PAES(1/4)-Br, crosslinked/branched PAES(1/4)Br-TAP copolymer shows roughly same IR spectrum (Fig. 5), but an enhanced peak at $2918 \mathrm{~cm}^{-1}$ and a wide peak at $3403 \mathrm{~cm}^{-1}$ in PAES(1/4)-Br-TAP spectrum are attributed to vibrations of methyl and hydroxyl group in TAP, respectively, indicating the incorporation of TAP into copolymer. XPS spectrum can also be employed to judge the crosslinking structure in PAES(1/4)-BrTAP. Although XPS spectra of $\mathrm{N} 1 \mathrm{~s}$ and $\mathrm{Br} 3 \mathrm{~d}$ can be utilized from a theoretical point of view, the $\mathrm{N} 1 \mathrm{~s}$ spectrum is hard to

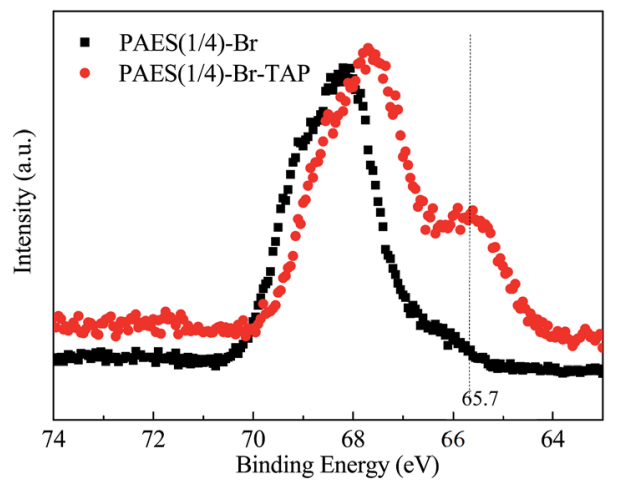

Fig. 7 XPS spectra (Br 3d) of PAES(1/4)-Br and PAES(1/4)-Br-TAP.

acquire because of very low nitrogen content resulting from low TAP crosslinker (3\%). In Br 3d spectra (Fig. 7), the signals at 68.0 and $65.7 \mathrm{eV}$ are attributed to the bonding energies of bromide in benzyl bromide and benzyl bromide based quaternary ammonium groups for PAES(1/4)-Br-TAP, respectively, despite that the two peaks are overlapped in some extent. These results demonstrate that TAP-based crosslinked/branched structure is formed in the resulting PAES(1/4)-Br-TAP, which is consistent with the literature result. ${ }^{36}$

\subsection{IEC, solubility and mechanical properties}

As listed in Table 1, DFBDM-based PAES anion exchange membranes have IEC values of 0.96-1.22 mequiv. $\mathrm{g}^{-1}$. The IECs are determined by a back titration method, where a soaking $\mathrm{HCl}$ solution $(0.01 \mathrm{M})$ of QPAES $(x / y)$ membrane sample is titrated by a $0.05 \mathrm{M} \mathrm{NaOH}$ standard solution. The IECs of the present membranes are comparable to those of the reported AEMs in literatures..$^{36,38-40}$

Solubility tests are carried out in kinds of solvents with the concentration of $5 \mathrm{wt} \%$ for DFBDM-based PAES copolymers, the results are shown in Table 3 . The present PAES copolymers exhibit good solubility for both $\operatorname{PAES}(x / y)$-Me and brominated $\operatorname{PAES}(x / y)$-Br, whereas PAES(1/4)-Br-TAP with a low crosslinking displays poor solubility in both aprotic solvents and common solvents even at elevated temperature. The poor solubility suggests that the crosslinked/branched structure is built in PAES(1/4)-Br-TAP membrane, which is in accordance with the

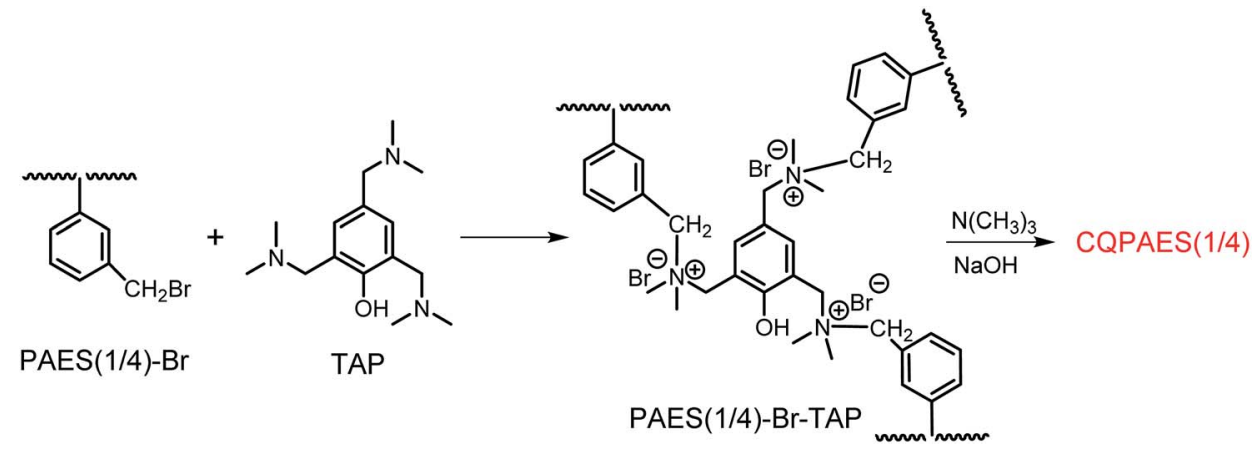

Fig. 6 Schematic diagram of the cross-linking reaction between PAES(1/4)-Br and TAP. 
Table 3 Solubility of side-chain type PAES ${ }^{a}$

\begin{tabular}{llllll}
\hline Code & $\mathrm{CHCl}_{3}$ & DMSO & NMP & DMAc & DMF \\
\hline PAES $(x / y)-\mathrm{Me}$ & ++ & + & ++ & ++ & ++ \\
$\operatorname{PAES}(x / y)-\mathrm{Br}$ & ++ & ++ & ++ & ++ & ++ \\
$\operatorname{PAES}(1 / 4)-\mathrm{Br}-\mathrm{TAP}$ & - & +- & +- & +- & +- \\
$\operatorname{QPAES}(x / y)$ CQPAES$(1 / 4)$ & - & - & - & - & -
\end{tabular}

a "++", soluble at room temperature; “+”, soluble at elevated temperature; "+-", partly soluble at elevated temperature; “-”, insoluble.

above XPS results. From Table 3, it can be seen that the solubility is further reduced after the quaternization, where QPAES $(x / y)$ and CQPAES(1/4) membranes are insoluble in the tested solvents even at elevated temperature for a long time.

The present PAES-based side-chain type membranes display reasonably high mechanical properties with Young's modulus (YM) of 1.04-1.27 GPa, maximum stress (MS) of 52.1261.55 $\mathrm{MPa}$, and elongation at break (EB) of $7.0-10.7 \%$, taking their viscosities into account. It is noted that the crosslinked membrane CQPAES(1/4) exhibits comparable mechanical properties to uncrosslinked QPAES(1/4), which maybe due to its low content of the crosslinked/branched structure in membrane.

\subsection{Water uptake and dimensional change}

For anion exchange membrane, hydroxide ion can be dissociated from quaternary ammonium hydroxide groups and transported in membrane from one side to another side, but these processes must be performed in water. Water absorbed in membrane not only guarantee the dissociation and transportation of hydroxide ion, but also ensure building a good interconnection of ion channels. A high water uptake (WU) is useful to increase hydroxide conductivity, but excessive WU will result in a large dimensional change and even partly soluble, which is harmful for applying the AEM in fuel cells because of the dimensional mismatch. Meanwhile, high WU also leads to a dilution of the hydroxide ion concentration in membrane and thus fail to achieve high conductivity. The WUs of PAES-based AEMs are listed in Table 1 , and the temperature dependence of WU is shown in Fig. 8.

It is found that WU increases obviously especially at high temperature $\left(80^{\circ} \mathrm{C}\right)$ with enhancing IEC value from 0.96 to 1.22 mequiv. $\mathrm{g}^{-1}$, and also improves largely with elevating temperature from 25 to $80^{\circ} \mathrm{C}$. Crosslinked membrane CQPAES(1/4) has lower WU (18.9\%) than the corresponding uncrosslinked membranes QPAES(1/4)-1 (23.8\%) and QPAES(1/4)-2 (29.8\%) at $80{ }^{\circ} \mathrm{C}$, which is attributed to its crosslinking structure and slightly lower IEC value. In addition, WU of CQPAES(1/4) is lower than that $(22.1 \%)$ of QPAES(1/3) with comparable IEC, indicating that the crosslinked structure restrict the polymer chain relaxation in water, thus suppressing the absorption of the water in membrane. Compared with the reported side-chain type membrane $\mathrm{Q}$ with IEC of 1.32 mequiv. $\mathrm{g}^{-1}$ and WU of $26.7 \%$ at $80{ }^{\circ} \mathrm{C},{ }^{36}$ the present membrane QPAES(1/4)-2 with slightly lower IEC of 1.22 mequiv. $\mathrm{g}^{-1}$ displays higher WU

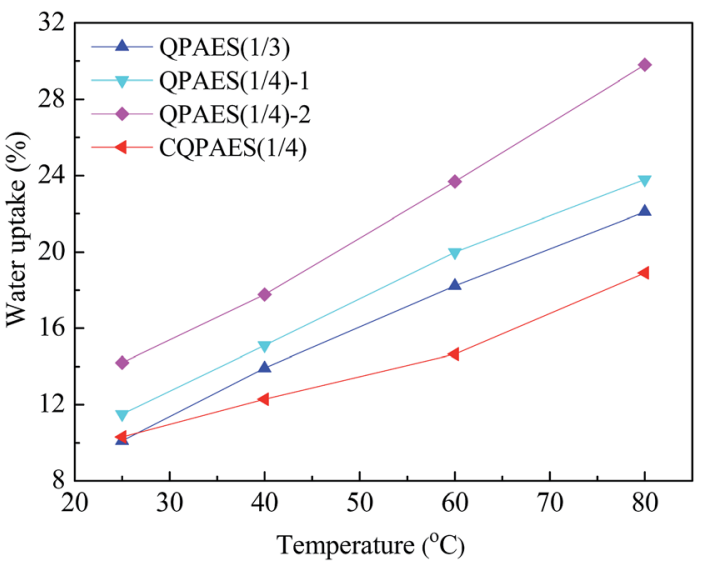

Fig. 8 Temperature dependence of WU for side-chain type QPAES $(x)$ y) and CQPAES(1/4).

(29.8\%), this may be due to easy aggregation of the pedant quaternary ammonium groups with greater hydrophilic sidechain length, resulting an improved water absorption.

To compare WUs among kinds of membranes with different IEC values, a more reasonable parameter, the number of absorbed water molecules per ionic group $(\lambda)$, is employed for both proton and hydroxide exchange membranes, ${ }^{36,37}$ and calculated via the equation, $\lambda=(10 \times \mathrm{WU}) /(18 \times \mathrm{IEC})$. The present DFBDM-based PAES membranes give $\lambda$ values of 11-14 at $80{ }^{\circ} \mathrm{C}$, which are comparable to the $\lambda$ values of the reported PAES-based AEMs functionalized by imidazolium salt (6-74 at $\left.60{ }^{\circ} \mathrm{C}\right)^{33,41}$ and by quaternary ammonium $\left(7-115\right.$ at $\left.80^{\circ} \mathrm{C}\right),,^{34,35,42}$ poly(arylene ether ketone)-based AEMs $\left(3-38\right.$ at $\left.80{ }^{\circ} \mathrm{C}\right),{ }^{13,39,43}$ but smaller than that of the reported PPO-based AEMs (24 at 70 $\left.{ }^{\circ} \mathrm{C}\right) .{ }^{28}$ It can be seen that the present uncrosslinked AEMs (QPAES(1/3) and QPAES(1/4)) have higher $\lambda$ values (12-14) than the reported membrane $\mathrm{Q}(\lambda \text { of } 11)^{36}$ due to its greater length and dense distribution of the pedant quaternary ammonium groups, which is in agreement with above WU.

The dimensional changes (through-plane and in-plane) of the present AEMs are shown in Table 1, and the temperature dependence of dimensional changes is drawn in Fig. 9. The present side-chain PAES-based AEMs exhibit membrane

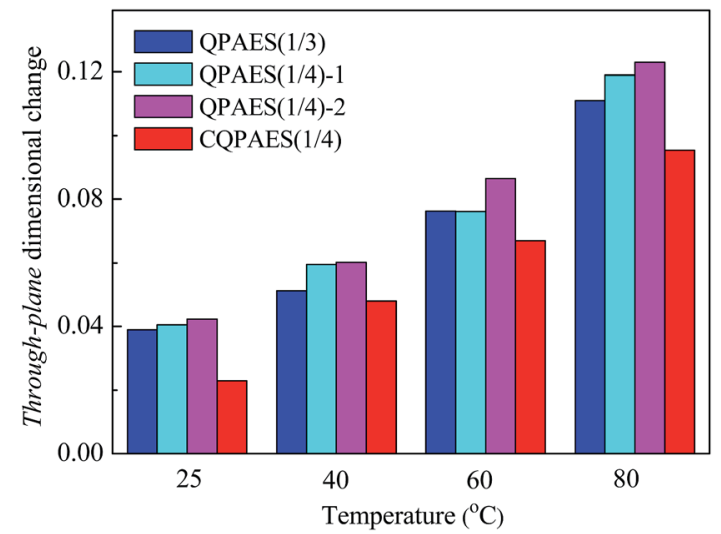

Fig. 9 Through-plane dimensional change of side-chain type AEMs in water. 
swelling ratio of $0.56-0.62$, indicating anisotropic membrane change with larger swelling in plane direction than in thickness one. This is consistent with the result of the reported side-chain type membrane $\mathrm{Q}(0.75),{ }^{36}$ but different from the case of PAESbased proton exchange membranes with isotropic membrane swelling. ${ }^{37}$ Similar to $\mathrm{WU}$, both through-plane and in-plane dimensional changes become large with increasing IEC value from 0.96 to 1.22 mequiv. $\mathrm{g}^{-1}$, and also increase with elevating temperature from 25 to $80{ }^{\circ} \mathrm{C}$. It is noted that the crosslinked membrane CQPAES(1/4) gives smaller dimensional changes than the corresponding uncrosslinked membranes (QPAES(1/ 4)) and the membrane QPAES(1/3) with comparable IECs. This is similar to the observations from WU. In addition, QPAES(1/4)2 with IEC of 1.22 mequiv. $\mathrm{g}^{-1}$ shows much larger dimensional change than the reported membrane $\mathrm{Q}$ (1.32 mequiv. $\mathrm{g}^{-1}$ ) despite of its low IEC value, which is attributed to its longer hydrophilic side-chain length, as described above for WU.

\subsection{Hydroxide conductivity and methanol permeability}

Hydroxide conductivity $(\sigma)$ is one of the most important properties for evaluating the application of AEM in fuel cells. The $\sigma$ generally depends on measurement conditions such as temperature and humidity, and also deeply relies on IEC and WU of the membrane. The $\sigma$ values in water and the corresponding apparent activation energy $\left(\Delta E_{\mathrm{a}}\right)$ of $\sigma$ for the present AEMs are calculated and summarized in Table 4, and the temperature dependence of $\sigma$ is described in Fig. 10. The $\Delta E_{\mathrm{a}}$ value $\left(15 \mathrm{~kJ} \mathrm{~mol}^{-1}\right)$ of the crosslinked membrane CQPAES(1/4) is slightly higher than that $\left(14 \mathrm{~kJ} \mathrm{~mol}^{-1}\right)$ of the membrane QPAES(1/3) despite of their same IEC values. The present PAES -based AEMs have comparable $\Delta E_{\mathrm{a}}$ values $\left(14-15 \mathrm{~kJ} \mathrm{~mol}^{-1}\right)$ to the reported AEMs $\left(5-21 \mathrm{~kJ} \mathrm{~mol}^{-1}\right) \cdot{ }^{36,43,44}$ Comparison of the $\Delta E_{\mathrm{a}}$ values between QPAES(1/4)-2 (15 kJ mol$\left.{ }^{-1}\right)$ and the reported membrane $\mathrm{Q}\left(10 \mathrm{~kJ} \mathrm{~mol}^{-1}\right)$ demonstrates that the longer pedant quaternary ammonium structures can effectively improve the conductivity. As shown in Table 4, the present side-chain type AEMs display reasonably high hydroxide conductivity in the range of $39.9-49.8 \mathrm{mS} \mathrm{cm}^{-1}$ at $80^{\circ} \mathrm{C}$, which is attributed to its better microphase separation (Fig. 11) resulted from the greater length of the pedant quaternary ammonium groups. As shown in Fig. 11, the dark and bright domains in AFM image are designated as the hydrophilic and hydrophobic phases,

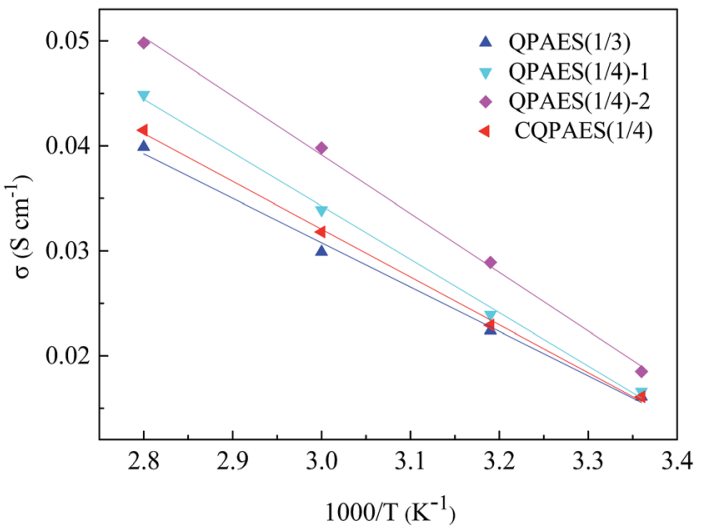

Fig. 10 Temperature dependence of hydroxide conductivity for sidechain type AEMs.

respectively. The surface images exhibit hydrophilic/ hydrophobic phase separation with an interconnected hydrophilic network of small ionic domains with size of 1-5 nm for QPAES(1/3), 2-9 $\mathrm{nm}$ for QPAES(1/4)-2 and 2-8 nm for CQPAES(1/ 4 ), respectively. It is obvious that the size of the ionic domains increases with enhancing hydrophilic units. After absorption of water, the dark domains will connect with each other and form the hydroxide ion transport channel. Moreover, the hydroxide conductivity increases largely with the temperature growing up from 25 to $80^{\circ} \mathrm{C}$, and also enhances obviously especially at $80^{\circ} \mathrm{C}$ with IEC value rising from 0.96 to 1.22 mequiv. $\mathrm{g}^{-1}$. Compared with the reported membrane $\mathrm{Q}\left(34 \mathrm{mS} \mathrm{cm}^{-1}\right)$, the higher $\sigma$ value for QPAES(1/4)-2 membrane $\left(49.8 \mathrm{mS} \mathrm{cm}^{-1}\right)$ is attributed to its higher WU and possible better microphase separation resulted from its greater length and dense distribution of the pedant quaternary ammonium groups. The $\sigma$ value of the crosslinked membrane CQPAES(1/4) is comparable to that of the membrane QPAES(1/3) with an equivalent IEC, but slightly lower than that of the corresponding uncrosslinked membranes (QPAES(1/4)) due to its lower IEC.

For reasonable comparison, the properties such as IEC, water uptake and conductivity of the representative AEMs reported in literatures are summarized in Table 5. It is found that the present uncrosslinked membrane QPAES(1/4)-2 exhibits higher hydroxide conductivity but relatively lower water uptake than the reported main-chain and side-chain type quaternary

Table 4 Hydroxide conductivity, oxidative stability, methanol permeability and the selectivity of side-chain type quaternized PAES membranes

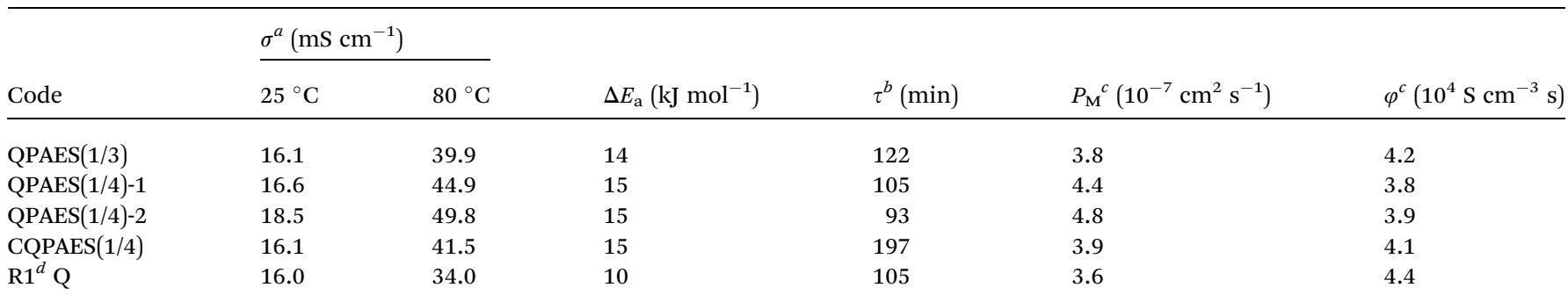

${ }^{a}$ In water, the experimental error is $\pm 5 \%{ }^{b} \tau$ : oxidative stability: the elapsed time that the membranes became broken in Fenton's reagent. ${ }^{c}$ At 32 wt $\%$ methanol solution and $25{ }^{\circ} \mathrm{C} .{ }^{d}$ Ref. 36 . 

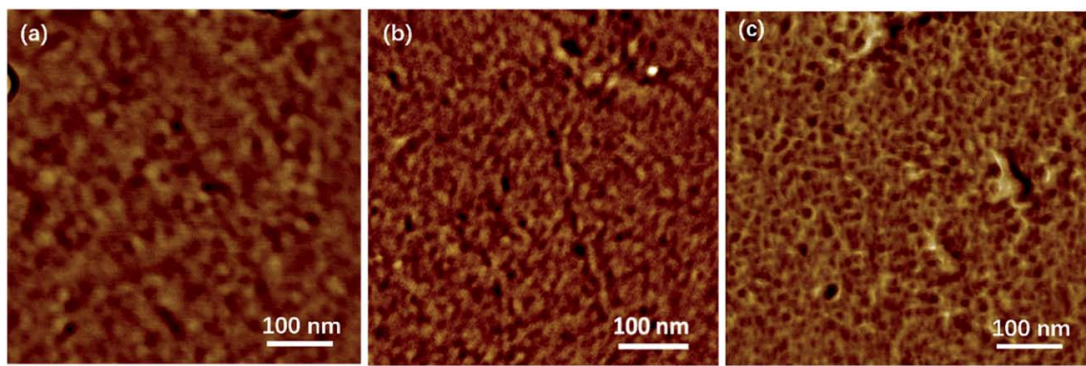

Fig. 11 AFM tapping phase images. (a) QPAES(1/3), (b) QPAES(1/4)-2 and (c) CQPAES(1/4).

Table 5 Comparison of IEC, WU, $\sigma, P_{\mathrm{M}}$ and $\varphi$ among anion exchange membranes

\begin{tabular}{|c|c|c|c|c|c|c|c|c|}
\hline \multirow{2}{*}{\multicolumn{2}{|c|}{ Membrane }} & \multirow[b]{2}{*}{ IEC (mequiv. $\mathrm{g}^{-1}$ ) } & \multirow[b]{2}{*}{$\mathrm{WU}^{a}(\%)$} & \multicolumn{2}{|c|}{$\sigma^{b}\left(\mathrm{mS} \mathrm{cm}^{-1}\right)$} & \multirow[b]{2}{*}{$P_{\mathrm{M}}^{c}\left(10^{-7} \mathrm{~cm}^{2} \mathrm{~s}^{-1}\right)$} & \multirow[b]{2}{*}{$10^{-4} \varphi\left(\mathrm{S} \mathrm{cm}^{-3} \mathrm{~s}\right)$} & \multirow[b]{2}{*}{ Ref. } \\
\hline & & & & $25{ }^{\circ} \mathrm{C}$ & $80{ }^{\circ} \mathrm{C}$ & & & \\
\hline \multicolumn{2}{|c|}{$\begin{array}{l}\text { QPAES(1/4)-2 } \\
\text { CQPAES(1/4) }\end{array}$} & 0.99 & 18.9 & 16.1 & 41.5 & 3.9 & 4.1 & This \\
\hline R1 & $\mathrm{Q}$ & 1.32 & 26.7 & 16 & 34 & 3.6 & 4.4 & 36 \\
\hline $\mathrm{R} 2$ & CQ5 & 1.27 & 23.4 & 15 & 32 & 1.2 & 12.5 & 36 \\
\hline R5 & QPECH/PTFE2 & 1.21 & $85\left(30^{\circ} \mathrm{C}\right)$ & 11 & 25 & & & 40 \\
\hline R6 & xPEEK-Q-100 & 1.18 & 14 & 14 & 36 & 2.9 & 4.8 & 39 \\
\hline R7 & Cr-PPO-g-Q72 & 1.89 & $26\left(90^{\circ} \mathrm{C}\right)$ & 39 & 85 & & & 44 \\
\hline $\mathrm{R} 8$ & PAES-Q-75 & $1.49 \pm 0.05$ & $59.6 \pm 3.1$ & $21.9 \pm 0.1$ & $47.3 \pm 0.1$ & & & 34 \\
\hline R9 & PAES-Q-90 & $1.68 \pm 0.04$ & $99.5 \pm 2.7$ & $39.2 \pm 0.2$ & $93.0 \pm 0.2$ & & & 34 \\
\hline $\mathrm{R} 10$ & MPAES-Q-1 & $1.00 \pm 0.00$ & $58.9 \pm 2.9$ & $12.6 \pm 0.2$ & $45.6 \pm 0.0$ & & & 34 \\
\hline $\mathrm{R} 15$ & QA-PES & 1.20 & 59 & 21 & 73 & & & 46 \\
\hline $\mathrm{R} 24$ & aQAPSF-1.27 & 1.27 & & 53.9 & 132.4 & & & 42 \\
\hline $\mathrm{R} 25$ & DMBP-TB & 0.82 & $36\left(30^{\circ} \mathrm{C}\right)$ & 23.5 & 164.4 & & & 31 \\
\hline
\end{tabular}

${ }^{a}$ At $80{ }^{\circ} \mathrm{C} .{ }^{b}$ In water at 25 (or 30) and $80{ }^{\circ} \mathrm{C} .{ }^{c}$ At $32 \mathrm{wt} \%$ methanol solution and $25{ }^{\circ} \mathrm{C}$.

ammonium functionalized poly(arylene ether) membranes with comparable IEC values (R1, R4, R5, R8, R10 and R11) ${ }^{34,36,39,40,43}$ and imidazolium functionalized AEM (R13), ${ }^{45}$ indicating that the present side-chain PAES-based AEM achieves a better balance between water uptake and hydroxide conductivity via introduction of DFBDM-based hydrophilic unit into copolymer. Meanwhile, compared to the present membrane QPAES(1/4)-2, the reported PAE-based AEMs, such as side-chain type quaternary ammonium functionalized $\mathrm{R} 9$ and imidazolium functionalized R14-R15, ${ }^{16,34,46}$ show higher hydroxide conductivity of 93, 85 and $73 \mathrm{mS} \mathrm{cm}^{-1}$, respectively, but they have much higher water uptakes of $99.5 \%, 83.5 \%\left(30{ }^{\circ} \mathrm{C}\right)$ and $59 \%$, respectively, which enhance the difficulty of the application in fuel cell. It can be seen that the present crosslinked membrane CQPAES(1/4) has reasonably higher hydroxide conductivity $\left(41.5 \mathrm{mS} \mathrm{cm}^{-1}\right)$ and lower water uptake $(18.9 \%)$ at $80{ }^{\circ} \mathrm{C}$ than the reported crosslinked AEMs (R2 and R6). ${ }^{36,39}$ It is noted that the reported quaternary ammonium functionalized AEM R24 (ref. 42) and microporous ionomer R25 containing the V-shape rigid Tröger's base $^{31}$ display much higher hydroxide conductivity than the present AEMs in spite of their low IECs.
For fuel cell application, AEM with small fuel crossover is needed to improve fuel utilization and avoid the loss of oxygen reduction at the cathode. Methanol permeability $\left(P_{\mathrm{M}}\right)$ is often employed to assess the level of methanol crossover for polymer electrolyte membrane. In addition, another more reasonable parameter calculated via ratio of conductivity to methanol permeability, $\varphi$, is also used to evaluate the membrane performance in fuel cell. ${ }^{36,37}$ As shown in Tables 5 and 6, the present membranes display the $P_{\mathrm{M}}$ in the range from $3.8 \times 10^{-7} \mathrm{~cm}^{2} \mathrm{~s}^{-1}$ to $4.8 \times 10^{-7} \mathrm{~cm}^{2} \mathrm{~s}^{-1}$ and the $\varphi$ values from $3.8 \times 10^{4} \mathrm{~S} \mathrm{~cm}^{-3} \mathrm{~s}$ to $4.2 \times 10^{4} \mathrm{~S} \mathrm{~cm}^{-3} \mathrm{~s}$, respectively, which are comparable to the reported AEMs (R1, R3, R4, and R6). ${ }^{36,38,39}$ It can be seen that the present crosslinked membrane CQPAES(1/4) displays obviously higher $P_{\mathrm{M}}\left(3.9 \times 10^{-7} \mathrm{~cm}^{2} \mathrm{~s}^{-1}\right)$ but smaller $\varphi\left(4.4 \times 10^{4} \mathrm{~S} \mathrm{~cm}^{-3}\right.$ s) than the reported TAP-based crosslinked membrane (R2 with $P_{\mathrm{M}}$ of $1.2 \times 10^{-7} \mathrm{~cm}^{2} \mathrm{~s}^{-1}$ and $\varphi$ of $\left.12.5 \times 10^{4} \mathrm{~S} \mathrm{~cm}^{-3} \mathrm{~s}\right),{ }^{36}$ this may be due to its low crosslinking degree and large dimensional change. It is noted that the present PAES-based AEMs have much smaller $P_{\mathrm{M}}$ but comparable $\varphi$ than the representative proton exchange membranes Nafion $112\left(P_{\mathrm{M}}\right.$ of $24 \times 10^{-7} \mathrm{~cm}^{2}$ 
Table 6 Mechanical properties of side-chain type AEMs before and

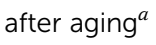

\begin{tabular}{lrllc}
\hline Code & $\begin{array}{l}\text { Aging time } \\
\text { (h) }\end{array}$ & YM (GPa) & MS (MPa) & EB (\%) \\
\hline QPAES(1/3) & 0 & 1.04 & 58.66 & 10.5 \\
& 120 & 1.00 & 53.18 & 5.96 \\
QPAES(1/4)-1 & 0 & 1.27 & 57.17 & 10.7 \\
& 120 & 1.15 & 49.84 & 7.45 \\
QPAES(1/4)-2 & 0 & 1.08 & 52.12 & 10.2 \\
& 120 & 0.95 & 48.99 & 7.12 \\
CQPAES(1/4) & 0 & 1.06 & 61.55 & 7.00 \\
& 120 & 1.01 & 59.73 & 5.24
\end{tabular}

${ }^{a}$ YM: Young's modulus; MS: maximum stress; EB: elongation at break, the experimental errors for YM, MS and EB are $\pm 5 \%$.

$\mathrm{s}^{-1}$ and $\varphi$ of $\left.4.2 \times 10^{4} \mathrm{~S} \mathrm{~cm}^{-3} \mathrm{~s}\right)$ and Nafion $117\left(P_{\mathrm{M}}\right.$ of $16 \times 10^{-7}$ $\mathrm{cm}^{2} \mathrm{~s}^{-1}$ and $\varphi$ of $\left.3.7 \times 10^{4} \mathrm{~S} \mathrm{~cm}^{-3} \mathrm{~s}\right) .{ }^{47,48}$

\subsection{Thermal, oxidative and alkaline stability}

As shown in Fig. 12, the present side-chain type AEMs show three-step degradation curves with decomposition of quaternary ammonium group during $170-300{ }^{\circ} \mathrm{C}$, decomposition of dibromomethyl and methyl groups during 300-400 ${ }^{\circ} \mathrm{C}$, and decomposition of polymer matrix above $400{ }^{\circ} \mathrm{C}$, respectively. The crosslinked membrane CQPAES(1/4) has slightly higher thermal stability than the uncrosslinked ones due to its crosslinking structures. The results reveal that the present membranes are stable under the common operation temperature for fuel cell.

Hydroxy and hydroperoxy radicals can be generally produced during fuel cell process, which has very strong oxidizability and thus brings negative effect on the durability of membrane. Oxidative stability is used to evaluate the membrane durability under hydroxy and/or hydroperoxy radical attacks, which is characterized by an elapsed time $(\tau)$ that a membrane sample (50 $\mu \mathrm{m}$ in thickness) crack in Fenton's reagent (3 wt\% $\mathrm{H}_{2} \mathrm{O}_{2}+$ 2 ppm $\mathrm{Fe}_{2} \mathrm{SO}_{4}$ ) at $80{ }^{\circ} \mathrm{C}$ with periodical shaking (about $10 \mathrm{~min}$ ). The oxidative stability of the present membranes is summarized in Table 4 . The present uncrosslinked AEMs have comparable

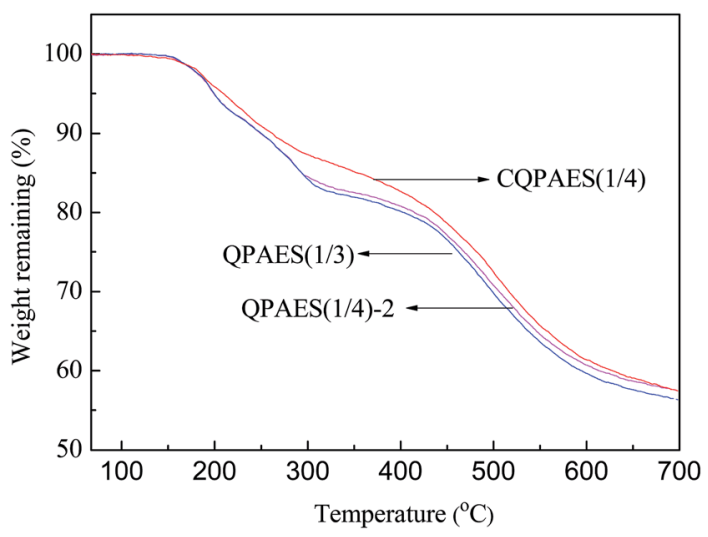

Fig. 12 TGA curves of side-chain type AEMs. oxidative stability ( $\tau$ of $93-122 \mathrm{~min}$ ) to the reported anion exchange membrane $\mathrm{Q}(\tau \text { of } 105 \mathrm{~min})^{36}$ despite of their higher water uptake and larger membrane swelling, suggesting that greater hydrophilic side-chain length is helpful to improve stability. This is possibly due to that the side-chain induced hydrophobic/hydrophilic phase separation in membrane restricts the domain of the hydroxy and/or hydroperoxy radical attacks, and thus depress the destructive effects. It is noted that the crosslinked membrane CQPAES(1/4) exhibits much higher oxidative stability than the corresponding uncrosslinked ones (QPAES(1/4)), as well as the membrane QPAES(1/3) with the same IEC. This may be due to its lower water uptake, lower dimensional change and covalent crosslinking structure. In addition, TAP-based crosslinking supplies phenolic antioxidant structure in membrane, this is also helpful to improve the oxidative stability. ${ }^{36}$

Alkaline stability of AEM is a total results of chemical stability, solubility stability and swelling-stress stability, which is an important topic for developing new AEM in recent years. Alkaline stability of the present membranes was investigated via an accelerated aging process, and characterized by the changes of both hydroxide conductivity and mechanical property before and after aging, where the membrane sample was immersed in $4 \mathrm{M} \mathrm{NaOH}$ solution at $80{ }^{\circ} \mathrm{C}$ for a given time, and then subjected to some characterization tests including hydroxide conductivity and mechanical property after washing and vacuum drying.

The change of mechanical property after aging treatment supplies the essential information about the chemical stability of polymer backbone. Quaternary ammonium functionalized PAES-based AEMs have been reported to completely lose mechanical property after aging in $0.6 \mathrm{M}$ KOD solution at $80{ }^{\circ} \mathrm{C},{ }^{49}$ indicating a great challenge for the application of PAESbased AEMs in fuel cell. Here, the mechanical properties of DFBDM-based PAES membranes before and after aging in $4 \mathrm{M}$ $\mathrm{NaOH}$ solution at $80{ }^{\circ} \mathrm{C}$ for $120 \mathrm{~h}$ are summarized in Table 6 . It can be seen that the aged membranes exhibit relatively high mechanical properties with YM above $0.95 \mathrm{GPa}$, MS above 48.99 MPa and EB above 5.24\%, which are slightly decreased (except for EB) compared with the membranes before aging, indicating excellent chemical stability for DFBDM-based PAES backbone and side-chain copolymer structure. Although the aging conditions including temperature, time and concentration of alkali solution are different from literature to literature, a rough comparison of the alkaline stability shows that the present side-chain type PAES shows slightly higher or comparable chemical stability than the reported AEMs in literatures. ${ }^{10,36}$

Besides, chemical stability of quaternary ammonium groups characterized by the change of hydroxide conductivity is most important concern for AEM application. The variation of hydroxide conductivity of DFBDM-based PAES membranes as a function of aging time is shown in Fig. 13(a). It is noted that the hydroxide conductivity decreases obviously for both crosslinked CQPAES(1/4) and uncrosslinked QPAES(1/4)-2, whereas CQPAES(1/4) has better chemical stability with a lower decrease amplitude of hydroxide conductivity (40\%) than QPAES(1/4)-2 $(60 \%)$ after aging $120 \mathrm{~h}$ in $4 \mathrm{M} \mathrm{NaOH}$ solution. Because the 

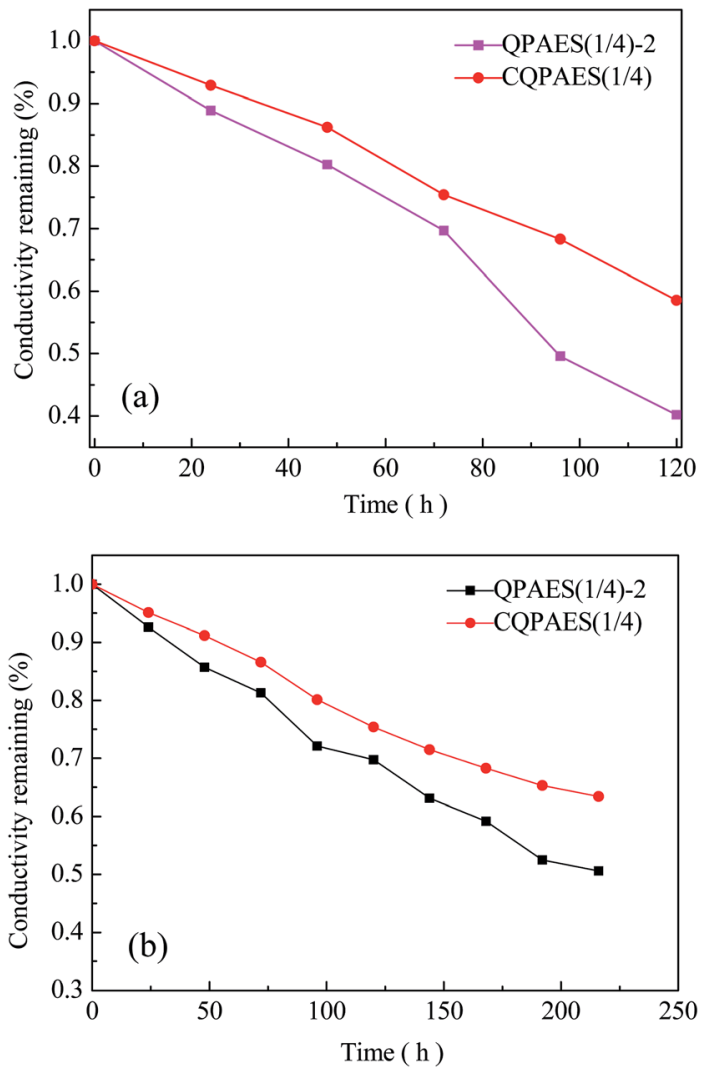

Fig. 13 Chemistry stability of side-chain type AEMs. (a) $4 \mathrm{M} \mathrm{NaOH}$ solution at $80^{\circ} \mathrm{C}$, (b) $1 \mathrm{M} \mathrm{NaOH}$ solution at $80^{\circ} \mathrm{C}$.

test conditions of alkaline stability are different from each other, a rough comparison of the alkaline stability is shown in Table 7.

It can be seen that the present AEMs display comparable chemical stability of anion groups to the reported main-chain and side-chain type quaternary ammonium functionalized
AEMs with comparable IEC values (R1, R9, R10, and R17), but slightly lower chemical stability (hydroxide conductivity remaining of $40-60 \%$ ) than the reported main-chain and sidechain type imidazolium functionalized AEMs (R19-R21), ${ }^{41,52,53}$ taking the high $\mathrm{NaOH}$ concentration and high temperature into account. It is also noted that the present AEMs exhibit much higher chemical stability of anion groups than some of the reported quaternary ammonium and imidazolium functionalized AEMs (R18 and R22). ${ }^{51,54}$ To further evaluate the alkaline stability, the aging is performed in $1 \mathrm{M} \mathrm{NaOH}$ solution at $80^{\circ} \mathrm{C}$ for $220 \mathrm{~h}$, and the results are listed in Table 7 and Fig. 13(b). It is found that QPAES(1/4)-2 and CQPAES(1/4) exhibit comparable chemical stability to the reported R16 and R17, ${ }^{50,51}$ but lower chemical stability than the reported R19 and R24. ${ }^{42,52}$ The difference on the alkaline stability of the membranes is probably resulted from their different microphase separation. The decreases in hydroxide conductivity are caused by the decomposition of anion groups, where the decomposition of the quaternary ammonium cations are due to hydroxide attacking via three possible processes, Hofmann elimination, $\mathrm{S}_{\mathrm{N}} 2$ nucleophilic substitution, and an ylide pathway that gives rise to unstable intermediates. ${ }^{55,56}$ For the present membranes, Hofmann elimination can be avoided because of the lack of $\beta$ hydrogen atom in benzyl-type quaternary ammonium hydroxide groups, which results in a high chemical stability of the quaternary ammonium. ${ }^{57,58}$ Therefore, the decomposition of the quaternary ammonium groups mainly involves the nucleophilic substitution induced by the hydroxide attacking for present side-chain PAES-based AEMs, which means that the decomposition increase with enhancing the hydroxide anion concentration. Although the membrane QPAES(1/4)-2 has much larger dimensional change due to its greater hydrophilic side-chain length, and absorbs more $\mathrm{NaOH}$ than the reported membrane $\mathrm{Q}$ (R1), ${ }^{36}$ they exhibit almost equivalent hydroxide conductivity remaining of about $40 \%$ after aging, suggesting a more stable chemical structure for pendant benzyl-type quaternary

Table 7 Comparison of alkaline stability among anion exchange membranes

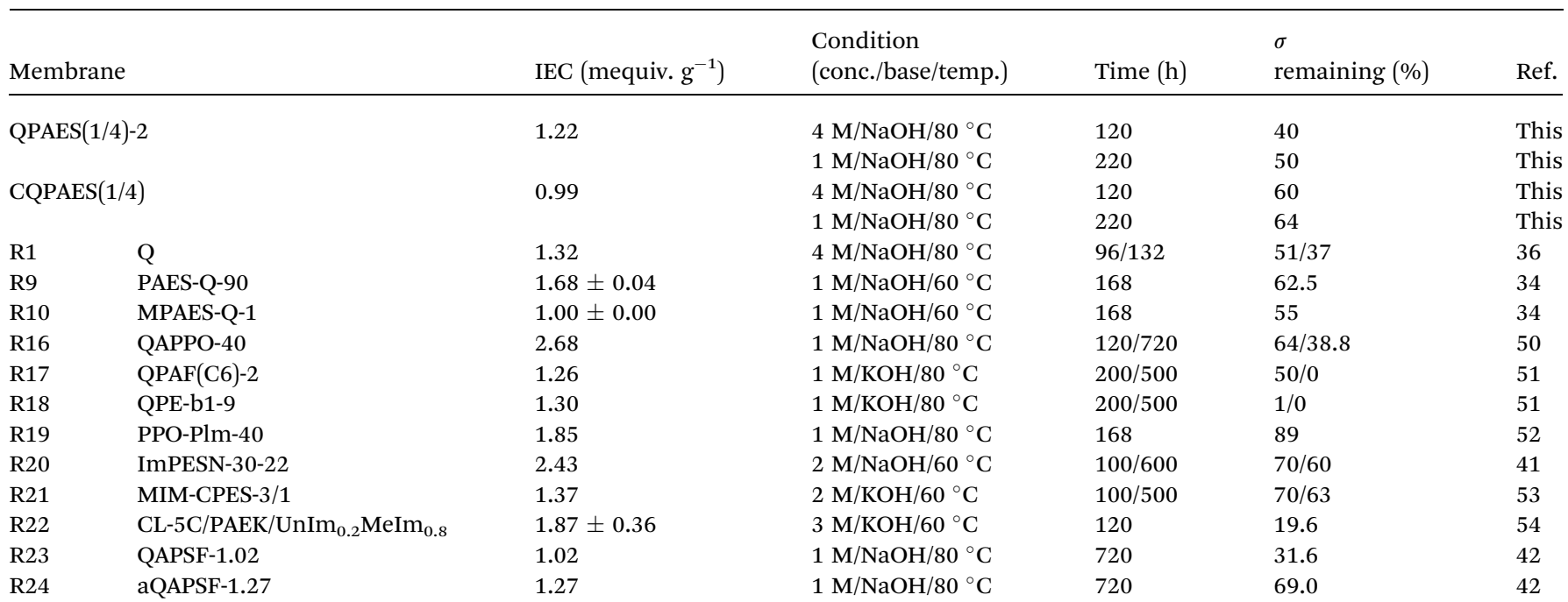


(1)

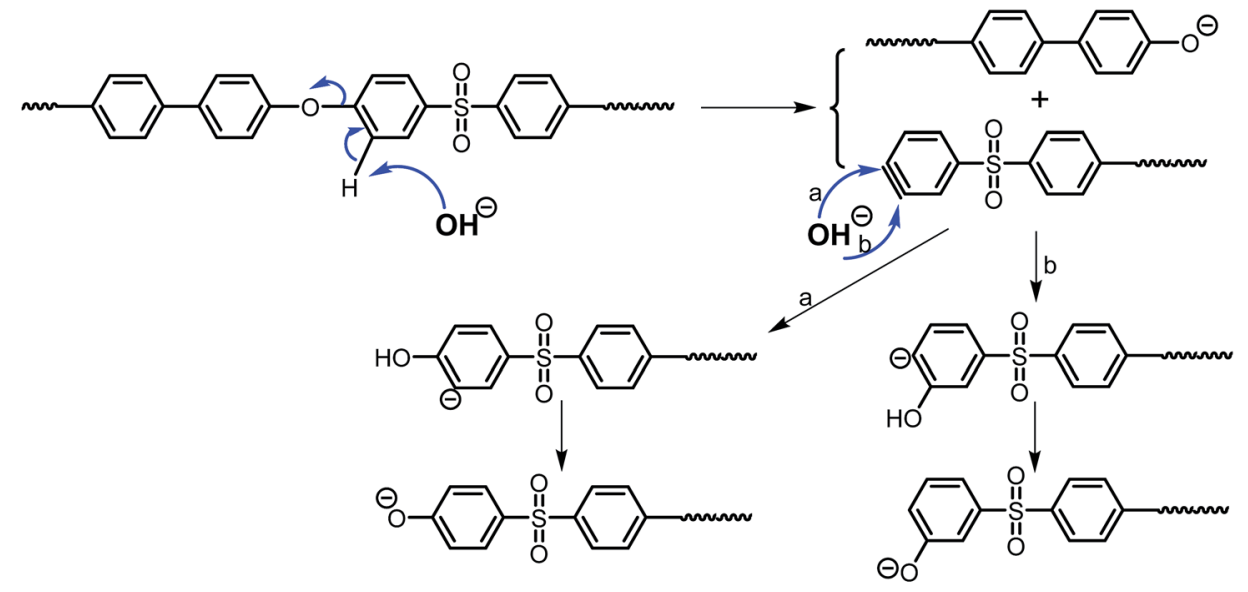

(2)

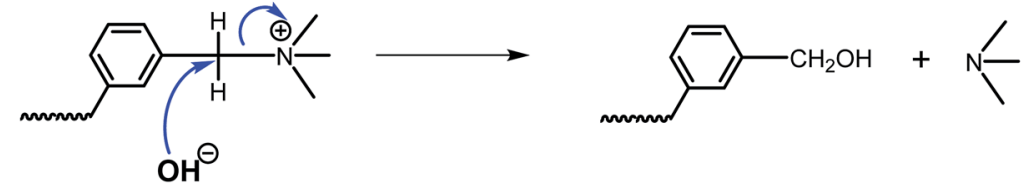

(3)

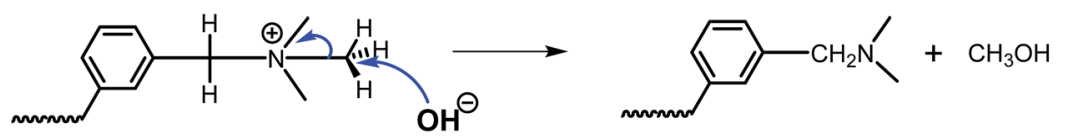

Fig. 14 Possible degradation of the copolymer backbone (1) and the benzyl-type quaternary ammonium (2 and 3) for QPAES( $x / y$ ).

ammonium hydroxide group with greater length. This should be useful for developing new AEMs with high performance.

Based on the above analysis, the possible degradation of $\operatorname{QPAES}(x / y)$ membranes by $\mathrm{OH}^{-}$attack is shown in Fig. 14, where the $\operatorname{QPAES}(x / y)$ copolymer backbone decomposes via substitution-addition process (1), and the benzyl-type quaternary ammonium decomposes via nucleophilic substitution (2 and 3). On the whole, the present AEMs have good alkaline stability with high chemical stability for both anion groups and DFBDM-based PAES matrix, taking the harsh aging condition $\left(4 \mathrm{M} \mathrm{NaOH}\right.$ at $\left.80^{\circ} \mathrm{C}\right)$ into account.

\section{Conclusion}

A new difluoro aromatic ketone monomer DFBDM is synthesized via a three-step reaction, while the corresponding sidechain type AEMs derived from DFBDM-based PAESs have been successfully prepared by polycondensation, bromomethylation and subsequent quaternization. The present membranes $\operatorname{QPAES}(x / y)$ exhibit higher conductivity than the reported side-chain type membrane $\mathrm{Q}$. The greater length and dense distribution of the pedant quaternary ammonium groups are probably responsible for the good hydroxide conductivity and high alkaline stability. The membrane QPAES(1/4)-2 has high hydroxide conductivity of $49.8 \mathrm{mS} \mathrm{cm}^{-1}$, low $P_{\mathrm{M}}$ of $4.8 \times$ $10^{-7} \mathrm{~cm}^{2} \mathrm{~s}^{-1}$ and large $\varphi$ of $3.9 \times 10^{4} \mathrm{~S} \mathrm{~cm}^{-3} \mathrm{~s}$, as well as high alkaline stability of both benzyl quaternary ammonium groups and side-chain type PAES copolymer matrix, respectively. The comprehensive performance can be further improved by TAPbased crosslinking with a low crosslinking degree.

\section{Acknowledgements}

The authors thanks for the financial support by the National Science Foundation Committee of China (51373092, 21543012), Program for Key Science \& Technology Innovation Team of Shaanxi Province (2015KCT-13), Key Technologies R\&D Program of Shaanxi Province (2014K10-06), Specialized Research Fund for the Doctoral Program of Higher Education (20130202120010), Program for Changjiang Scholars and Innovative Research Team in University (IRT_14R33), and the Fundamental Research Funds for the Central Universities (GK201703030, GK201603058, GK201501007, GK201501002).

\section{References}

1 H. Zhang and P. K. Shen, Chem. Rev., 2012, 112, 2780-2832. 2 E. H. Yu, X. Wang, U. Krewer, L. Li and K. Scott, Energy Environ. Sci., 2012, 5, 5668-5680.

3 G. F. McLean, T. Niet, S. Prince-Richard and N. Djilali, Int. J. Hydrogen Energy, 2002, 27, 507-526.

4 Y.-J. Wang, J. Qiao, R. Baker and J. Zhang, Chem. Soc. Rev., 2013, 42, 5768-5787.

5 G. Couture, A. Alaaeddine, F. Boschet and B. Ameduri, Prog. Polym. Sci., 2011, 36, 1521-1557.

6 G. Merle, M. Wessling and K. Nijmeijer, J. Membr. Sci., 2011, 377, 1-35.

7 J. R. Varcoe, P. Atanassov, D. R. Dekel, A. M. Herring, M. A. Hickner, P. A. Kohl, R. Anthony, A. R. Kucernak, W. E. Mustain, K. Nijmeijer, K. Scott, T. Xu and L. L. Zhuang, Energy Environ. Sci., 2014, 7, 3135-3191. 
8 J. Cheng, G. He and F. Zhang, Int. J. Hydrogen Energy, 2015, 40, 7348-7360.

9 J. Pan, S. F. LuF, Y. Li, A. B. Huang, L. Zhuang and J. T. Lu, Adv. Funct. Mater., 2010, 20, 312-319.

10 Z. Xia, S. Yuan, G. Jiang, X. Guo, J. Fang, L. Liu, J. Qiao and J. Yin, J. Membr. Sci., 2012, 390-391, 152-159.

11 D. J. Kim, C. H. Park and S. Y. Nam, Int. J. Hydrogen Energy, 2016, 41, 7649-7658.

12 S. P. Ertem, T. H. Tsai, M. M. Donahue, W. Zhang, H. Sarode, Y. Liu, S. Seifert, A. M. Herring and E. B. Coughlin, Macromolecules, 2016, 49, 153-161.

13 Z. Zhang, K. Shen, L. Lin and J. Pang, J. Membr. Sci., 2016, 497, 318-327.

14 F. Zhang, H. Zhang and C. Qu, J. Mater. Chem., 2011, 21, 12744-12752.

15 X. Yan, S. Gu, G. He, X. Wu and J. Benziger, J. Power Sources, 2014, 250, 90-97.

16 Y. Z. Zhuo, A. L. Lai, Q. G. Zhang, A. M. Zhu, M. L. Ye and Q. L. Liu, J. Mater. Chem. A, 2015, 3, 18105-18114.

17 J. H. Wang, S. H. Li and S. B. Zhang, Macromolecules, 2010, 43, 3890-3896.

18 S. Gu, R. Cai and Y. Yan, Chem. Commun., 2011, 47, 28562858.

19 S. Gu, R. Cai, T. Luo, Z. Chen, M. Sun, Y. Liu, G. He and Y. Yan, Angew. Chem., Int. Ed., 2009, 48, 6499-64502.

20 J. R. Varcoe, R. C. T. Slade, E. L. H. Yee, S. D. Poynton, D. J. Driscoll and D. C. Apperley, Chem. Mater., 2007, 19, 2686-2693.

21 Y. Luo, J. Guo, C. Wang and D. Chu, Macromol. Chem. Phys., 2011, 212, 2094-2102.

22 J. Pan, Y. Li, J. Han, G. Li, L. Tan, C. Chen, J. Lu and L. Zhuang, Energy Environ. Sci., 2013, 6, 2912-2915.

23 J. Yan, H. D. Moore, M. R. Hibbs and M. A. Hickner, J. Polym. Sci., Part B: Polym. Phys., 2013, 51, 1790-1798.

24 D. Chen and M. A. Hickner, ACS Appl. Mater. Interfaces, 2012, 4, 5775-5781.

25 J. Yan and M. A. Hickner, Macromolecules, 2010, 43, 23492356.

26 J. Zhou, M. Unlu, J. A. Vega and P. A. Kohl, J. Power Sources, 2009, 190, 285-292.

27 M. R. Hibbs, C. H. Fujimoto and C. J. Cornelius, Macromolecules, 2009, 42, 8316-8321.

28 K. H. Gopi, S. G. Peera, S. D. Bhat, P. Sridhar and S. Pitchumani, Int. J. Hydrogen Energy, 2014, 39, 2659-2668.

29 N. Li, Y. Leng, M. A. Hickner and C.-Y. Wang, J. Am. Chem. Soc., 2013, 135, 10124-10133.

30 X. Lin, J. R. Varcoe, S. D. Poynton, X. Liang, A. L. Ong, J. Ran, Y. Li and T. Xu, J. Mater. Chem. A, 2013, 1, 7262-7269.

31 Z. Yang, R. Guo, R. Malpass-Evans, M. Carta, N. B. McKeown, M. D. Guiver, L. Wu and T. Xu, Angew. Chem., Int. Ed., 2016, 55, 11499-11502.

32 N. J. Robertson, H. A. Kostalik, T. J. Clark, P. F. Mutolo, HcD. Abruna and G. W. Coates, J. Am. Chem. Soc., 2010, 132, 3400-3404.

33 Y. Q. Yang, J. Wang, J. F. Zheng, S. H. Li and S. B. Zhang, J. Membr. Sci., 2014, 467, 48-55.
34 X. Li, G. Nie, J. Tao, W. Wu, L. Wang and S. Liao, ACS Appl. Mater. Interfaces, 2014, 6, 7585-7595.

35 C. Wang, B. Shen, C. Xu, X. Zhao and J. Li, J. Membr. Sci., 2015, 492, 281-288.

36 J. Zhou, P. Chen, Q. Weng, J. Fang, X. Chen and Z. An, Int. J. Hydrogen Energy, 2016, 41, 5765-5775.

37 P. Chen, X. Chen, Z. An, K. Chen and K. Okamoto, Int. J. Hydrogen Energy, 2011, 36, 12406-12416.

38 S. Xu, G. Zhang, Y. Zhang, C. Zhao, W. Ma, H. Sun, N. Zhang, L. Zhang, H. Jiang and H. Na, J. Power Sources, 2012, 209, 228-235.

39 S. Xu, G. Zhang, Y. Zhang, C. Zhao, L. Zhang, M. Li, J. Wang, N. Zhang and H. Na, J. Mater. Chem., 2012, 22, 13295-13302.

40 T. Y. Guo, Q. H. Zeng, C. H. Zhao, Q. L. Liu, A. M. Zhu and I. Broadwell, J. Membr. Sci., 2011, 371, 268-275.

41 A. N. Lai, L. S. Wang, C. X. Lin, Y. Z. Zhuo, Q. G. Zhang, A. M. Zhu and Q. L. Liu, ACS Appl. Mater. Interfaces, 2015, 7, 8284-8292.

42 C. Chen, J. Pan, J. Han, Y. Wang, L. Zhu, M. A. Hickner and L. Zhuang, J. Mater. Chem. A, 2016, 4, 4071-4081.

43 K. Z. Shen, Z. P. Zhang, H. B. Zhang, J. H. Pang and Z. H. Jiang, J. Power Sources, 2015, 287, 439-447.

44 J. Ran, L. Wu, Q. Ge, Y. Chen and T. Xu, J. Membr. Sci., 2014, 470, 229-236.

45 W. Wang, S. Wang, W. Li, X. Xie and Y. Lv, Int. J. Hydrogen Energy, 2013, 38, 11045-11052.

46 A. H. N. Rao, R. L. Thankamony, H. J. Kim, S. Nam and T. H. Kim, Polymer, 2013, 54, 111-119.

47 K. Okamoto, Y. Yin, O. Yamada, M. Islam, T. Honda, T. Mishima, Y. Suto, K. Tanaka and H. Kita, J. Membr. Sci., 2005, 258, 115-122.

48 D. S. Kim, G. P. Robertson, Y. S. Kim and M. D. Guiver, Macromolecules, 2009, 42, 957-963.

49 S. A. Nunez and M. A. Hickner, ACS Macro Lett., 2013, 2, 4952.

50 J. Pan, L. Zhu, J. J. Han and M. A. Hickner, Chem. Mater., 2015, 27, 6689-6698.

51 H. Ono, J. Miyake, S. Shimada, M. Uchida and K. Miyatake, J. Mater. Chem. A, 2015, 3, 21779-21788.

52 X. Liao, Y. Gong, Y. Liu, D. Zuo and H. Zhang, RSC Adv., 2015, 5, 99347-99355.

53 Y. Z. Zhuo, A. N. Lai, Q. G. Zhang, A. M. Zhu, Y. Ling and Q. Liu, J. Membr. Sci., 2015, 491, 138-148.

54 Y. X. Xu, J. S. Yang, N. Y. Ye, M. Teng and R. H. He, Eur. Polym. J., 2015, 73, 116-126.

55 S. Chempath, B. R. Einsla, L. R. Pratt, C. S. Macomber, J. M. Boncella, J. A. Rau and B. S. Pivovar, J. Phys. Chem. C, 2008, 112, 3179-3182.

56 S. Chempath, J. M. Boncella, L. R. Pratt, N. Henson and B. S. Pivovar, J. Phys. Chem. C, 2010, 114, 11977-11983.

57 D. Stoica, L. Ogier, L. Akrour, F. Alloin and J. Fauvarque, Electrochim. Acta, 2007, 53, 1596-1603.

58 C. Iojoiu, F. Chabert, M. Marechal, N. E. Kissi, J. Guindet and J. Sanchez, J. Power Sources, 2006, 153, 198-209. 